\title{
The role of added feed enzymes in promoting gut health in swine and poultry
}

\author{
Elijah Kiarie $^{1 *}$, Luis F. Romero ${ }^{1}$ and Charles M. Nyachoti ${ }^{2}$ \\ ${ }^{1}$ DuPont Industrial Biosciences-Danisco Animal Nutrition, Marlborough, Wiltshire SN8 1 XN, UK \\ ${ }^{2}$ Department of Animal Science, University of Manitoba, MB Winnipeg, Canada R3T 2N2
}

\section{Abstract}

The value of added feed enzymes (FE) in promoting growth and efficiency of nutrient utilisation is well recognised in single-stomached animal production. However, the effects of FE on the microbiome of the gastrointestinal tract (GIT) are largely unrecognised. A critical role in host nutrition, health, performance and quality of the products produced is played by the intestinal microbiota. FE can make an impact on GIT microbial ecology by reducing undigested substrates and anti-nutritive factors and producing oligosaccharides in situ from dietary NSP with potential prebiotic effects. Investigations with molecular microbiology techniques have demonstrated FE-mediated responses on energy utilisation in broiler chickens that were associated with certain clusters of GIT bacteria. Furthermore, investigations using specific enteric pathogen challenge models have demonstrated the efficacy of FE in modulating gut health. Because FE probably change the substrate characteristics along the GIT, subsequent microbiota responses will vary according to the populations present at the time of administration and their reaction to such changes. Therefore, the microbiota responses to FE administration, rather than being absolute, are a continuum or a population of responses. However, recognition that FE can make an impact on the gut microbiota and thus gut health will probably stimulate development of FE capable of modulating gut microbiota to the benefit of host health under specific production conditions. The present review brings to light opportunities and challenges for the role of major FE (carbohydrases and phytase) on the gut health of poultry and swine species with a specific focus on the impact on GIT microbiota.

Key words: Pigs: Poultry: Feed enzymes: Gastrointestinal health: Microbiota

Amongst biotechnological additives, feed enzymes (FE) for swine and poultry have made the most progress and impact in the past decade. Generally, the enzyme systems available for the animal feed industry are derived from microbes (fungi and bacteria) through traditional submerged liquid fermentation ${ }^{(1)}$ or solid-state fermentation ${ }^{(2)}$. Recent estimates indicate that FE saved the global feed market an estimated US $\$ 3-5$ billion per year ${ }^{(3)}$. This value emanated from considerable investment in application research leading to strategic developments in the use of FE and, as a result, the creation of a global FE market worth in excess of US $\$ 650$ million and growing $^{(3,4)}$. Phytase currently dominates this market, taking $60 \%$ share, carbohydrase $30 \%$ and the rest (proteases, lipases, etc.) $10 \%{ }^{(3)}$. Rapid growth in the last decade has been associated with the acceptance of phytase in replacing inorganic phosphates and the wider use of carbohydrases in maize-based diets to mitigate spiralling feed costs and minimise nutrient excretion. The carbohydrase market is accounted for by two dominant enzymes: xylanases and cellulases. Other commercially available carbohydrases include $\alpha$-amylase, $\beta$-mannanase, $\alpha$-galactosidase and pectinase ${ }^{(3)}$.

The role of FE in improving the productive value of diets for single-stomached animals has received extensive reviews, for example, Bedford \& Schulze ${ }^{(5)}$, Adeola \& Cowieson $^{(3)}$, Woyengo \& Nyachoti ${ }^{(6)}$ and Slominski ${ }^{(7)}$. In this context, several modes of action have been proposed, namely: (1) hydrolysis of specific chemical bonds in feedstuffs that are not sufficiently degraded or indeed not at all by the animal's own enzymes (for example, mixed salts of phytic acid); (2) elimination of the nutrient-encapsulating effect of the cell wall polysaccharides and therefore increased availability of starches, amino acids and minerals; (3) breakdown of anti-nutritional factors that are present in many feed ingredients (for example, soluble NSP and phytic acid); (4) solubilisation of insoluble NSP for more effective hindgut fermentation and thus improved overall energy utilisation; and (5) complementation of the enzymes (for example, amylase, protease, lipase)

Abbreviations: AGP, antimicrobial growth promoter; AXOS, arabinoxylooligosaccharides; DP, degree of depolymerisation; ETEC, enterotoxigenic Escherichia coli; FCR, feed conversion ratio; FE, feed enzyme; GIT, gastrointestinal tract; NE, necrotic enteritis; NSPases, NSP-degrading carbohydrases; $\mathrm{SD}$, swine dysentery.

*Corresponding author: Dr Elijah Kiarie, fax +44 1672 517778, email elijah.kiarie@dupont.com 
produced by young animals where, because of the immaturity of their own digestive system, endogenous enzyme production may be inadequate.

Recent price volatility of traditional feed ingredients suggests that the swine and poultry industries will continue to seek alternative cost-effective feed ingredients such as cereal co-products from biofuel and milling industries ${ }^{(8)}$. However, the successful application of alternative ingredients will be dependent on the characterisation of their nutritive value, availability of technologies for mitigating risks associated with them (for example, mycotoxins, anti-nutritional factors) and potential economic benefits when formulated correctly into swine and poultry diets. As an example, the high NSP and indigestible protein contents in cereal co-products can limit their inclusion into pig feed $^{(9)}$; however, supplemental NSP-degrading enzymes and proteases might allow high inclusion of such feedstuffs. The ability to find and evolve the next generation of FE will be driven by understanding the target substrates and the implications to animal nutrition ${ }^{(10)}$. However, the gastrointestinal tract (GIT) is populated with diverse assemblages of microbiota that play a critical role not only for the overall well-being of the animal, but also for its nutrition, performance and quality of its products. In this context, there is a clear need to understand the role of $\mathrm{FE}$ in influencing gut health through modulation of the gastrointestinal microbiota. The present review is an attempt to summarise current thinking in this area, underscore mechanisms, and suggest opportunities for expanded exploitation of FE biotechnology.

\section{Swine and poultry gut microbiomes}

A complex and dense community of bacteria, archaea, fungi, protozoa and viruses inhabits the gut of the pig and the chicken. Indeed, the total number of microbial cells within the GIT of single-stomached animals, including man, exceeds that of the host cells by at least one order of magnitude ${ }^{(11)}$. The GIT microbiome exhibits a gradient concentration, with numbers and diversity increasing from proximal to distal. For example, in pigs, the stomach and proximal small intestine contain relatively low numbers of bacteria $\left(10^{3}-10^{5}\right.$ bacteria/g or $\mathrm{ml}$ of contents); with dominant bacteria being Lactobacillus spp. and Streptococcus spp. ${ }^{(12)}$. In contrast, the distal small intestine harbours a more diverse and numerically greater $\left(10^{8}\right.$ bacteria/g or $\mathrm{ml}$ of contents) population of bacteria ${ }^{(13)}$. In broiler chickens, analysis of $16 \mathrm{~S}$ rDNA gene sequences revealed thirteen, eleven, fourteen, twelve, nine and fifty-one operational taxonomic units in the crop, gizzard, duodenum, jejunum, ileum and caecum, respectively ${ }^{(14)}$. Radial distribution of microbes within specific GIT segment has also been described ${ }^{(13)}$. The four micro-habitats include: the intestinal lumen; the unstirred mucus layer or layer that covers the mucosal epithelium; the deep mucus layer found in the crypts; and the surface of the intestinal epithelial cells. The diversity of bacterial populations within a particular micro-habitat in the GIT is influenced by factors such as digesta flow rate, $\mathrm{pH}$, anoxic conditions, types of endogenous and dietary substrates, inhibitory factors such as bacteriocins and SCFA, and competitive advantage ${ }^{(13,15)}$. Given this scenario, it is likely that certain nutrients and their associated physico-chemical effects play a major role in maintaining the balance of the microflora in specific micro-habitats, and subsequently in determining whether a pathogenic bacterium proliferates.

A significant hindrance in studying the gut microbiome has been the inability to effectively identify and quantify microbial species, their metabolic endproducts, and mechanisms by which they affect host health ${ }^{(16,17)}$. This is mainly because the bulk of available information is limited to cultivable microbiota. The fraction of micro-organisms that are cultivable remains low mainly because the growth requirements of most of the bacteria are unknown, but also because of the selectivity of the isolation media that are used, the stress imposed on bacteria by the cultivation procedures, the need for anoxic conditions and problems simulating the microbe-microbe and microbehost interactions that occur naturally in the gut ${ }^{(16)}$. Some of these issues have been overcome by the increased use of culture-independent, molecular-based techniques that use the sequence diversity of the $16 \mathrm{~S}$ rDNA gene to explore the diversity and abundance of bacterial communities within the GIT of animals. The use of $16 \mathrm{~S}$ rDNA sequencing has been applied to analyse the intestinal bacterial community in a number of species, including swine and poultry, and has shown that the majority of the bacterial species colonising the GIT have not been cultured and characterised $^{(18,19)}$. These data provide crucial information on the community structure in the GIT, but they provide limited information on microbe-microbe and hostmicrobe interactions ${ }^{(18)}$. Microbes in the GIT have evolved mechanisms to influence the intestinal environment for their own benefit, and potentially that of the host, by influencing epithelial host cell gene expression ${ }^{(13,16)}$. Host-microbe interaction is currently a very active area of research and may help in identifying clusters of GIT bacteria that are consistently associated with better growth performance and health in animals raised in varied environments ${ }^{(17,20)}$

\section{Concept of dietary approaches to gastrointestinal health}

The primary functions of the GIT are to digest and absorb nutrients from the diet and to excrete waste products. As alluded to, the GIT also contain normal microbiota responsible for a plethora of functions including intestinal development and functionality (as evidenced by differences seen between gnotobiotic and conventional animals), nutrient digestion and absorption, mucus secretion, immune development and cytokine expression ${ }^{(13,21,22)}$. However, there are many specific 
bacterial pathogens that also inhabit the GIT, and they generally cause disease when the gut ecosystem is disturbed in some manner. For example, in the post-weaning period in pigs, numbers of pathogenic Escherichia coli proliferate to exceed those of other bacterial populations, resulting in clinical disease ${ }^{(23)}$. Many factors influence the diversity and activity of the GIT microbiota, including the age of the animal and the environment it inhabits, antimicrobial agents (antibiotics and minerals such as $\mathrm{Zn}$ and $\mathrm{Cu}$ ), dietary composition (for example, type and content of carbohydrates and protein), feed additives (for example, organic acids; FE), feeding methods (fermented liquid feeding), disease load, weaning, season, stress and genetics $^{(13,15,16,17)}$. These factors, which usually interact, can make comparison of studies on gut microbiota a daunting task.

One question that generally arises in relation to the GIT microbiome, and particularly the area of gut 'health', is: what is 'normal' when referring to the health of the pig and chicken gut? Hillman ${ }^{(24)}$ suggested that emphasis should be placed on an 'optimal' GIT microbiota rather than a 'normal' microbiota being present, because it is very difficult to define what is 'normal' given the wide array of conditions that pigs and chickens are grown under. Producers strive to keep pigs and chickens free of infections (bacteria, viruses, parasites) and achieve the best utilisation of feed for muscle gain and egg production as possible. However, with at least 400 species of bacteria, with numbers as high as $10^{14}$ colony-forming units/g inhabiting the $\operatorname{GIT}^{(11,25)}$, it is little wonder that perturbations sometimes occur to cause clinical disease and occasionally death $^{(12,26)}$. Specific enteric pathogens can cause enormous economic loss to pig and poultry enterprises; hence there is interest in being able to identify, quantify and track the different components of the microbiota (both pathogenic and non-pathogenic) to improve health and production. To check microbial perturbations the industry has long depended on dietary fortification with sub-therapeutic levels of antibiotics and antimicrobial growth promoters $(\mathrm{AGP})^{(26,27)}$. However, long-term use of AGP has been linked to the potential problem of increasing transferable resistance of bacteria to antimicrobial drugs ${ }^{(28)}$ and has been banned outright in some jurisdictions and increasingly under intense scrutiny in others.

Interest in alternatives to AGP has increased recently as there is a clear need to control enteric pathogens previously contained through the use of AGP in feeds. For example, in poultry there is greater risk of an outbreak of necrotic enteritis (NE) with the use of viscous grains (barley, wheat and rye) ${ }^{(29-31)}$. This has been associated with high digesta viscosity, decreased nutrient digestibility and prolonged intestinal transit time, thus favouring growth of Clostridiumperfringens in the upper gut ${ }^{(32)}$. In swine, viscous fibres have also been linked to exacerbation of post-weaning collibacillosis (for example, McDonald et al. ${ }^{(33,34)}$, Hopwood et $a l^{(35)}$ and Montagne et $a l .{ }^{(36)}$ ) and swine dysentery (SD) (for example, Durmic et $a l^{(37,38)}$ and Pluske et $\left.a l .{ }^{(39,40)}\right)$. The detrimental effects of soluble fibres in swine have been associated with increasing digesta viscosity, undigested nutrients in the GIT and endogenous secretions. Furthermore, an increased flow of ileal undigestible protein in the hindgut can result in proteolytic fermentation in the large intestine of pigs and the caecum of poultry that can negatively affect their performance and health ${ }^{(41,42)}$. Arguably, the use of AGP in the past markedly reduced the negative consequences of feeding such feedstuffs and as a result performance was maintained on diets that otherwise would be problematic. Indeed, earlier studies demonstrated that the growth-depressing effect of viscous rye was ameliorated by antibiotic supplementation ${ }^{(43,44)}$. Furthermore, Smulders et al. ${ }^{(41)}$ showed that antibiotics were more effective in diets with low digestible protein content $v$. in diets with high digestible protein content. Consequently, there is considerable interest in identifying alternative nutritional strategies for managing the microbiota of pigs and chickens when fed antibiotic-free diets.

\section{Influence of feed enzymes on the gastrointestinal microbiota}

Enzymes are biological catalysts that speed up reactions and act on specific substrates or reactants. Arguably, characteristics of FE are designed and set by the producing organism given its ecology (substrate). However, the efficacy in animal feed applications depends very much on a completely different set of criteria which are based on the mechanism of action in animal nutrition ${ }^{(5)}$. The link between FE and the GIT microbiome can perhaps be better understood from two points of view (Fig. 1). On one hand are the effects of substrates by themselves on the digesta biochemical characteristics and GIT physiology and on the other hand is the modification of these effects by $\mathrm{FE}$ to the extent that the substrates are degraded or modified in the GIT. This view is important because the rationale for the development and application of FE is to target certain dietary substrates (such as phytate and NSP) that are not degraded sufficiently or indeed not at all by the endogenous digestive enzyme array in the GIT. For example, an accepted paradigm in broiler chickens is that increased intestinal viscosity due to soluble NSP is the most important mechanism for poor growth and feed utilisation ${ }^{(3,5,45)}$ However, the viscous nature of soluble NSP is a digesta biochemical characteristic that is accompanied by or precipitates many small intestine physiological responses such as increased digesta transit times ${ }^{(46)}$, intestinal mass and turnover rates of mucosa cells ${ }^{(47-49)}$, mucin and carbohydrate expression of goblet cell glycoconjugates ${ }^{(50)}$ and undigested constituents ${ }^{(45,51)}$. These responses have been shown to increase small intestine microbial activity, composition and size $\mathrm{e}^{(45,52)}$. Conversely, supplemental 
NSP-degrading carbohydrases (NSPases, such as xylanase and $\beta$-glucanase) reduce digesta viscosity by partial or complete hydrolysis of soluble NSP, improving animal performance and nutrient utilisation but also effecting changes to the composition and metabolic potential of bacterial populations ${ }^{(45,52,53)}$.

The literature evidence suggests that diet composition is a strong modulator of the composition of the gut

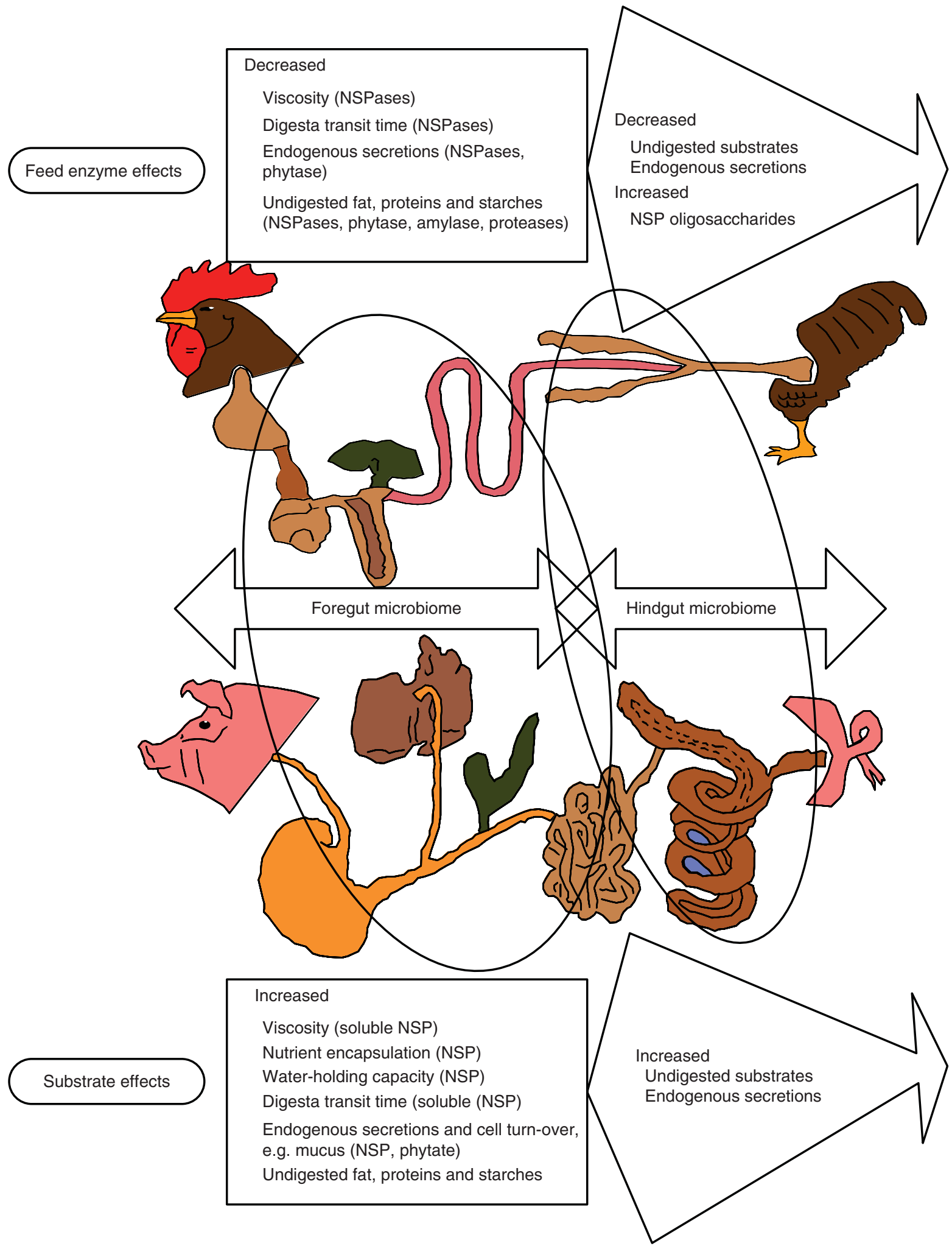

Fig. 1. Link between feed enzymes and gut microbiota in poultry and swine. NSPases, NSP-degrading carbohydrases. (A colour version of this figure can be found online at http://www.journals.cambridge.org/nrr) 
microbiota. For example, the relative contributions of host genetics and diet in shaping the gut microbiota was investigated using wild-type mice and ApoA-I knockout counterparts (genetically modified for impaired glucose tolerance) fed different diets using DNA fingerprinting and bar-coded pyrosequencing of $16 \mathrm{~S}$ rRNA genes ${ }^{(54)}$. These investigations revealed that 57 and $12 \%$ variation of gut microbiota in mice was accounted for by the diet and genetic background, respectively, suggesting the primacy of diet in determining the composition of the gut microbiota. Within the context of interaction between FE and GIT microbiota, the view (Fig. 1) that FE act on specific components of feed ingredients in most cases explains the role of $\mathrm{FE}$ in modulating the gut microbiota. However, it is also plausible that some enzymes such as alkaline phosphatase can act directly on the microbiota by dephosphorylating the outer membrane ${ }^{(55,56)}$, but as far as we know alkaline phosphatases are not a major FE and there is a dearth of data demonstrating their effects on gut microbiota. In view of the foregoing, it has been suggested that FE might influence the intestinal microbiota through two main mechanisms: reducing the undigested substrates; and creating (in situ) short-chain oligosaccharides from cell wall NSP with potential prebiotic effects. These two mechanisms and the more recent findings will now be discussed.

\section{Reducing undigested substrates}

The diversity of the microbiome in a gut section reflects in part the types of nutrient substrates in those sections. Bacteria in the GIT derive most of their carbon and energy from luminal compounds (dietary and/or endogenous) which are either resistant to attack by digestive fluids or absorbed so slowly by the host that bacteria can successfully compete for them. Indeed, it has been suggested that the performance improvement attributes of AGP are due to factors such as reduced competition for nutrients in the small intestine, reduced local inflammation due to control of pathogens, and reduced size of intestine ${ }^{(57,58)}$. Since bacterial species differ in their substrate preferences and growth requirements, the chemical composition and structure of the digesta largely determine the species distribution of the bacterial community in the GIT. Consequently, bacterial community structure and metabolic function are very much dependent upon digesta biochemical conditions, as a result of feed composition and attendant host physiological responses such as endogenous secretions. For example, Apajalahti et $a l{ }^{(59)}$ analysed bacteria chromosomal DNA content of guanine and cytosine $(G+C)$ in caecal digesta samples from broiler chickens fed either maize- or wheatbased diets. Compared with wheat, maize favoured low $\% \mathrm{G}+\mathrm{C}$ microbes $(20-34 \%)$ at the expense of the higher $\% \mathrm{G}+\mathrm{C}$ bacteria (55-59\%). In swine, Drew et al. ${ }^{(60)}$ reported changes in gut bacterial populations in pigs fed diets containing maize, barley or wheat as the main carbohydrate source, and correlated some changes with the fibre content of the diets. From the foregoing, it is clear that bacterial species differ in their substrate preferences and growth requirements; the chemical composition and structure of the digesta largely determine the species distribution of the bacterial community in the GIT. Consequently, it is important to understand that FE will mediate or modulate microbial status preset by the main dietary ingredients (target substrates).

When digestion is compromised, the flow of undigested/ unabsorbed nutrients into the hindgut increases ${ }^{(45,51)}$ and the microbial ecology can change dramatically ${ }^{(52)}$. Bird et $a l .{ }^{(61)}$ compared pigs fed highly digestible starch (low amylose) and low digestible starch (mixture of nonheated and heated high amylose). Low starch digestibility had a dramatic effect on intestinal physico-chemical and microbial characteristics. The study also reported increased caecum weight and colon length in pigs fed low digestible starch and this was linked to a large flow of digesta into the hindgut that stimulated gut mass growth. These findings were replicated in a more recent pig study (Regmi et al. $\left.{ }^{(62)}\right)$ that showed that slowly digestible starch resulted in poor feed efficiency concomitant with an increased flow of DM, starch and protein in the hindgut. Dietary fibre and in particular soluble NSP have been shown to have dramatic effects on the flow of undigested DM into the hindgut. For example, Jørgensen et al. ${ }^{(51)}$ showed that increasing dietary fibre from 6 to $27 \%$ resulted in a 5- to 6 -fold increase in the flow of digesta through the terminal ileum of pigs. In broiler chickens, the addition of soluble NSP $(40 \mathrm{~g} / \mathrm{kg}$ ) isolated from wheat to a sorghum-based diet reduced the ileal digestibility of starch and protein by more than $35 \%{ }^{(45)}$. The implications of increased concentration of undigested substrates in the GIT are such that the microbiota proliferates and competes with the host for the available nutrients, and increase the risk of microbial perturbation if the balance is tipped for pathogen growth ${ }^{(15)}$. Furthermore, the host responds to increased undigested substrates by increasing the gut mass which carries a cost in terms of increased maintenance requirements which ultimately compromise efficiency of growth ${ }^{(63,64)}$. It is inevitable that the use of any additive that influences the digestibility of the diet will change the selection pressures on the resident microbiota which in turn will moderate the efficiency with which the host utilises its feed.

\section{Phytase}

Phosphorous is the third most expensive nutrient in diets for non-ruminants; however, the majority (>65\%) of the phosphorous in feedstuffs of plant origin is bound in mixed salts of phytic acids and is unavailable to the animal without enzymic dephosphorylation ${ }^{(65)}$ Phytase, the requisite enzyme to hydrolyse phytic acids, is insufficient in avian and mammalian pancreatic and 
intestinal secretions, present in some feedstuffs and ubiquitous in microbial systems ${ }^{(66,67)}$. Consequently, to provide adequate phosphorous to non-ruminant farm animals it is necessary to include feedstuffs with high phosphorous availability such as inorganic supplements (for example, dicalcium phosphate) or animal-based feedstuffs (for example, meat and bone meal) in the diet. While this approach is plausible for adequate phosphorous nourishment, it creates three challenges: excessive excretion of phosphorous in the manure; expensive diets; and considerable demand on non-renewable global reserves for rock phosphate ${ }^{(65)}$. Cognisant of the fact that the extent of the use of supplemental sources of phosphorous in the diets for non-ruminants depends on the digestible phosphorous content of the basal vegetable feedstuffs, research and commercial efforts have been directed at improving utilisation of phytic acid in these feedstuffs. To this end, the use of exogenous microbial phytase is almost ubiquitous in poultry and swine feeds and has received numerous reviews (for example, Adeola \& Cowieson $^{(3)}$, Slominski ${ }^{(7)}$ and Woyengo \& Nyachoti $\left.{ }^{(6)}\right)$.

Mixed salts of phytic acid can also exert anti-nutritional effects through the increased endogenous $\mathrm{N}$ losses and formation of complexes with proteins and other nutrients $^{(66-72)}$. For example, Onyango et al. ${ }^{(71)}$ reported that phytic acid increased mucin and endogenous amino acid losses from the GIT of chickens. Several theories have been proposed as to the mechanism of how phytate binds to protein and reduce its digestibility. It is believed that at an acidic $\mathrm{pH}$, a binary protein-phytate complex may form where phytate can bind to the $\alpha-\mathrm{NH}_{2}$ groups and side chains of the basic amino acids arginine, histidine and lysine ${ }^{(68,69)}$. Indeed, in recent digestive tract simulation studies, Yu et al. ${ }^{(72)}$ demonstrated that degradation of phytate to lower-level esters dramatically increased the solubility of soya and casein proteins.

Consequences of anti-nutritive effects of phytic acid are that ileal digestibility of dietary protein is reduced and endogenous secretions, in particular of mucin, are increased $^{(69)}$. It is therefore plausible that phytic acid destruction through supplemental phytase would result in reduced endogenous losses and increased protein digestibility, thus limiting protein supply to the hindgut and exerting microbiota changes. There is, however, a dearth of information on the effects of phytase on the gut microbiome in single-stomached animals. Lumpkins et al. ${ }^{(73)}$ showed that phytase reduced intestinal $5 \mathrm{AC}$ mucin mRNA abundance in broiler chickens. Clostridium thrives on mucin, and a reduction in mucin levels could correspond to a reduction in $C$. perfringens and the occurrence of $\mathrm{NE}^{(74)}$. Increased caecal acetate was reported in broiler chickens fed phytase, an indication of microbial activity modulation ${ }^{(75)}$. In pigs, supplemental phytase was observed to increase Clostridium group in the ileum without changing total bacterial numbers ${ }^{(76)}$ and Bifidobacterium and Clostridium numbers ${ }^{(77)}$ in the ileum. In a more recent pig study, Rostagno et al. ${ }^{(78)}$ observed that the addition of alkaline phosphatase to a phosphorous-deficient diet ( $80 \%$ requirement) reduced the ileal digesta count of Enterococci, whereas the addition of alkaline phosphatase to a diet adequate in phosphorous reduced coliforms, aerobes and anaerobes. Interestingly, alkaline phosphatase had no effect on caecal or faecal microflora in both phosphorous-inadequate and -adequate diets. It is well documented that intestinal alkaline phosphatase is highly efficacious in dephosphorylating free bacterial lipopolysaccharides, a component of the outer membrane of Gram-negative bacteria ${ }^{(55,56)}$. The outer membrane in Gram-negative bacteria plays an important role in nutrient uptake and provides the organism with a remarkable permeability barrier, conferring resistance to a variety of detergents and antibiotics ${ }^{(79)}$. In view of the foregoing, it can be speculated that dephosphorylation of the lipopolysaccharides within the bacterial outer membrane might compromise viability of the bacteria. However, in vitro experiments indicated that the exogenous intestinal alkaline phosphatase was unable to directly alter the growth, surface biology or invasiveness of live, intact bacteria ${ }^{(55,80)}$. Few studies have investigated the effects of fed alkaline phosphatase on gut microbiota. For example, alkaline phosphatase promoted restoration of the normal gut microbiota following antibiotic exposure and inhibited Salmonella colonisation in mice; however, it also appeared to provide a favourable environment for $E$. coli growth ${ }^{(80)}$. Malo et al. ${ }^{(80)}$ opined that alkaline phosphatase may not exert its effects on the gut microbiota via direct mechanisms, but rather via mechanisms related to reduction of the mucosal microenvironment $\mathrm{pH}$ through luminal ATP dephosphorylation, altered inflammatory status following lipopolysaccharide detoxification or some other not yet known factors. Nonetheless, the foregoing pig studies seem to suggest that phytic acid-dephosphorylating enzymes make an impact on microbiota in the small intestine more than in the hindgut; however, the implications of such changes in terms of gut health are yet to be understood.

\section{Carbohydrases and proteases}

It has recently been reported that the beneficial effects of FE are inextricably linked to the amount of the undigested fat, protein and starch in the ileum ${ }^{(81)}$. For example, Romero et $a l .{ }^{(82)}$ fed broiler chicken two types of diets, a simple maize-soya diet (maize-SBM) and a complex diet in which maize-SBM was fortified with dried distillers grains with solubles and rapeseed meal in line with the current trends in the industry to seek alternative ingredients to curb feed costs. The results (Fig. 2) showed that a blend of xylanase, amylase and protease improved ileal digestibility of starch, fat and protein and thus significantly improved the bird's ability to extract energy in two distinctly different diets in terms of substrate complexity. 
(A)

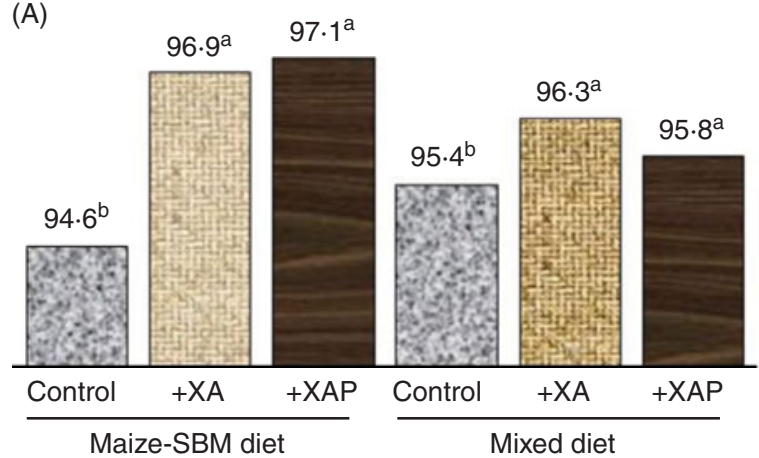

(C)

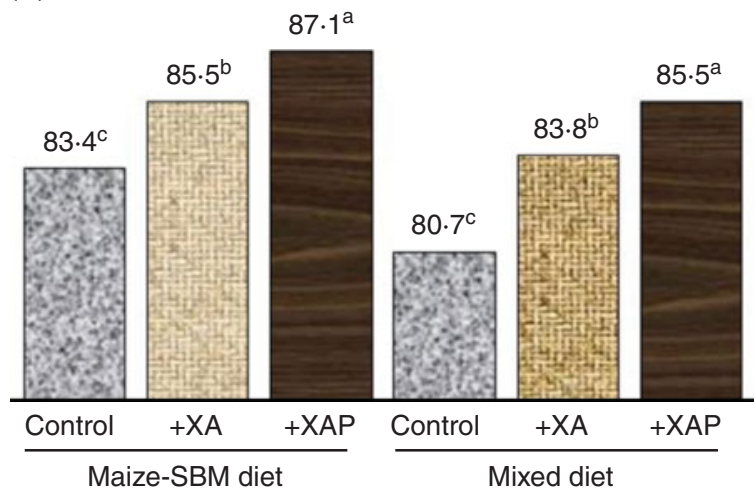

(B)

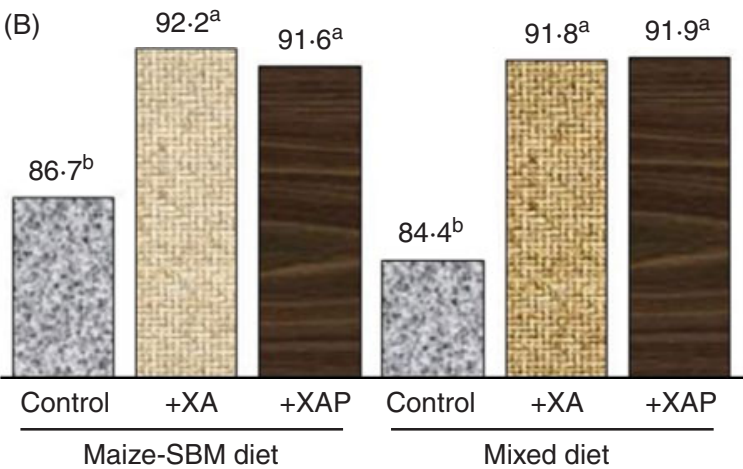

(D)

Fig. 2. lleal digestibility (\%) of starch (A), fat (B), protein (C) and their contribution ( $\mathrm{JJ} / \mathrm{kg}$ diet) to dietary energy (D) in maize-soya (maize-SBM) or maize-soya diets with $10 \%$ dried distillers grains and $5 \%$ rapeseed meal (mixed) fed to broiler chickens as influenced by enzyme combinations containing xylanase and amylase (XA), or xylanase, amylase and protease (XAP). (D) $\sqsubset$, Protein; $\sqsubset$, fat; $\sqsubset$ starch. Xylanase was from Trichoderma reesei at 2000 units/kg feed; amylase was from Bacillus lichiniformis at 200 units $/ \mathrm{kg}$ feed; protease was from B. subtilis at 4000 units $/ \mathrm{kg}$ feed. ${ }^{\mathrm{a}, \mathrm{b}, \mathrm{c}}$ Mean values with unlike superscript letters within a subgrouping were significantly different $(P<0.05)$. Adapted from Romero et al. ${ }^{(82)}$ (A colour version of this figure can be found online at http://www.journals. cambridge.org/nrr).

Such accelerated intestinal digestion and removal of what would otherwise be apparently undigested without FE must clearly limit the nutrients available for the microbes.

Indeed, Torok et al. ${ }^{(53)}$ used the terminal restriction fragment length polymorphism method to examine changes in gut microbial communities in response to the addition of an NSP-degrading enzyme product containing $\beta$-glucanase, xylanase and protease activities in a barley-based diet. The enzyme product improved growth performance and energy utilisation compared with the control. Further correlation analysis of the dietary apparent metabolisable energy and microbial community composition within the ileum and caeca revealed distinct clusters associated with control and enzyme-supplemented birds. This is one of few studies that directly linked differences in the composition of the gut microbial community with improved performance, implying that the presence of specific beneficial and/or absence of specific detrimental bacterial species may have contributed to the improved performance in birds receiving FE. Furthermore, this study is a clear indication that molecular techniques coupled with statistical methods are capable of identifying desirable and undesirable clusters of organisms as far as good performance is concerned. Previous reports showed that supplemental carbohydrases reduced caecal counts of Campylobacter jejuni in broilers ${ }^{(50)}$ and Brachyspira intermedia in the laying hen ${ }^{(83)}$. Clearly, FE might have dramatically altered the caecum ecology to the extent that for these specific bacteria growth was not favourable.

\section{Short-chain oligosaccharides with potential prebiotic effects}

Usage of NSP-degrading enzymes (NSPases; xylanase, $\beta$-glucanase, $\beta$-mannanase, $\alpha$-galactosidase and pectinase) is common in poultry and swine feeds. As reviewed by Simon ${ }^{(84)}$, NSPases targeting NSP may have several modes of action: partial hydrolysis of NSP, decrease in digesta viscosity, and rupturing of NSP-containing cell walls, thereby making the encapsulated nutrients available for digestion. Partial hydrolysis of soluble and insoluble NSP and rupturing of NSP-containing cell walls have been associated with reduced recovery of NSP when feedstuffs were incubated with NSPases ${ }^{(85,86)}$. Furthermore, studies investigating the efficacy of NSPases reported not only improvement of nutrient digestibilities but also digestibility of $\mathrm{NSP}^{(3,7)}$. Although there are some studies in which no effect of added NSPases on nutrients 
digestibility was recorded, for example, as reviewed by Adeola \& Cowieson $^{(3)}$, if the added NSPases in the diet do achieve the intended purpose they do so by partially hydrolysing the substrate, i.e. dietary NSP. It is possible that part of the variation in the response of NSPases on NSP utilisation is related to interactions with the gut microbiota, which have a role in the utilisation of undigested substrates in the intestinal lumen.

In commercial human food production, short-chain oligosaccharides are extracted from natural sources as is the case for the galacto-oligosaccharides from soyabeans, but they can also be obtained biochemically ${ }^{(87)}$. Indeed, in the food industry, enzymic hydrolysis processes are applied for production of a whole array of oligosaccharides from plant cell wall polysaccharides ${ }^{(87,88)}$. As outlined by Voragen $^{(87)}$, the concept for manufacturing oligosaccharides from suitable polysaccharides is simple: starting from a polysaccharides-rich feedstock followed by controlled hydrolysis of some of the heterocyclic ester bonds of the main chain backbone by an exogenous enzyme to give compounds of a lower degree of polymerisation (DP). For example, the enzymic hydrolysis process is widely applied in the commercial production of fructo-oligosaccharides from inulin ${ }^{(89)}$. Manufactured sources of oligosaccharides may allow the dose to be more precisely defined and controlled, but only a very limited range of oligosaccharide structures is presently available. Most are linear, with short chain length and containing only one or two different sugar units, and are specially manufactured for the everincreasing human market.

Plant and plant co-products used by the feed industry contain almost an unlimited range of polysaccharides (Table 1). The use of specific NSPases, singly or in combination, against a range of polysaccharides can generate very large numbers of oligomer mixtures ${ }^{(89)}$. However, the NSP listed in Table 1 represent general classes in which there is commonality of overall structure but considerable variation in fine structure. For example, while the underlying structure of most arabinoxylans is similar, i.e. a $\beta$-1,4-linked backbone of $D$-xylose residues, in practice the variety is enormous due to differences in

Table 1. Carbohydrate contents ( $\mathrm{g} / \mathrm{kg} \mathrm{DM})$ and major NSP in common feedstuffs*

\begin{tabular}{|c|c|c|c|}
\hline Ingredient & $\begin{array}{l}\text { Carbo- } \\
\text { hydrate† }\end{array}$ & $\begin{array}{l}\text { Total } \\
\text { NSP }\end{array}$ & Major NSP \\
\hline Maize & 830 & 119 & Cellulose, arabinoxylans \\
\hline Wheat & 814 & $78-129$ & Arabinoxylans, xyloglucan \\
\hline Barley (hulled) & 823 & 167 & Mixed-linked $\beta$-glucan \\
\hline Oat (hulled) & 787 & 232 & Mixed-linked $\beta$-glucan \\
\hline Soyabean meal & 400 & 148 & $\begin{array}{l}\text { Galacturonans, arabinans, } \\
\text { galactomannan }\end{array}$ \\
\hline Rapeseed meal & 454 & 171 & (Arabino) $\beta-1,4$-galactan \\
\hline Flaxseed meal & 493 & 271 & Pectic polymers, arabinoxylans \\
\hline
\end{tabular}

backbone size and in type and degree of substitutions from the backbone, all of which depend on the source of arabinoxylan ${ }^{(90)}$. For example, xylan hydrolysis products from maize are different from those produced from wheat in terms of the size, degree of substitution and in quantity ${ }^{(91,92)}$. Even when the source of polysaccharide is constant (i.e. same grain), fine structure can vary with age, environmental conditions of growing and between varieties. For example, Austin et al. ${ }^{(93)}$ showed that partial degradation of arabinoxylan from twelve UK-grown wheat samples with an endoxylanase (single cloned) resulted in mixtures of up to twelve oligosaccharides, with each differing in the presence and relative proportions of these oligomers. Such an observation suggested that even when the enzyme has only one activity, it is likely that polysaccharides will uniquely release a mixture of oligomers. Importantly, such divergence in products of enzyme activity will probably influence the in vivo response observed.

Regardless of whether a crude or purified enzyme product is used to hydrolyse NSP in typical diets for non-ruminants, it follows that short-chain oligosaccharides must be generated on every occasion when NSPases are used as feed additives. In this context, Apajalahti \& Bedford ${ }^{(94)}$ showed that the addition of xylanase in wheat-based broiler diets resulted in a 5-fold increase in concentrations of short-chain xylooligomers $(<10 \mathrm{DP})$ in the caecum. There are apparently few studies where the in situ generation of oligosaccharides has been monitored in pigs and chickens fed diets containing NSPases. However, since oligosaccharides will be among the hydrolysis products released when NSPases degrade NSP, a question has been raised as to whether the presence of such products would influence GIT ecology ${ }^{(15,89,95)}$. This is because the resulting NSP hydrolysis products may modulate intestinal microflora ${ }^{(15,89)}$. Numerous reports in pigs indicated that supplemental NSPases increased intestinal SCFA and this was associated with increased abundance and activity of specific bacteria communities such lactobacilli ${ }^{(96-98)}$. In chickens, abundance of Enterobactreacea was reduced in caeca when birds were offered cereal-based diets with supplemental NSPases ${ }^{(99,100)}$. Furthermore, Choct et al. ${ }^{(45,101)}$ linked increased concentration of SCFA in the caecum of chickens fed diets with supplemental xylanase to increased flow of xylo-oligomers into the caecum. However, as the in situ production of short-chain oligosaccharides was not monitored in the aforementioned studies, it is thus rather difficult to associate observed microbial activity with the presence or absence of NSP hydrolysis products.

Short-chain xylo-oligosaccharides (arabinoxylooligosaccharides; AXOS) derived from the in vitro hydrolysis of wheat bran with an endoxylanase and fed to broiler chickens resulted in increased bifidobacteria populations in the caecum and improvements in feed conversion ratio (FCR) on both wheat- and maize-based diets ${ }^{(102)}$. Interestingly, in the same study some birds were fed diets supplemented with xylanase instead of AXOS and the scale of the 
improvement in FCR achieved was equal for both strategies. This suggests that the production of fermentable oligomers may well be a large part of the total response to FE supplementation, although it was noted that the xylanase did not influence the intestinal flora to the same extent as that of the oligosaccharides, suggesting the xylanase, at the levels used, may not have released similar quantities of AXOS in situ. As the majority of arabinoxylans in feedstuffs are insoluble ${ }^{(103)}$, perhaps the xylanase used was not as effective in solubilising and cleaving insoluble NSP to effective oligomer sizes under limiting gut conditions (for example, digesta transit time). The effects on FCR were of similar magnitude in both the maize- and wheat-based diets, suggesting that caecal fermentation may be of significance. Xylo-oligosaccharides are not digestible or are very poorly digestible up to the ileumcaecum junction, but are fermented in part by microbiota in the caecum with concomitant production of SCFA and thus provision of extra energy to the birds. This might partly explain the reason why FCR improved with feeding AXOS in both maize- and wheat-based diets. It is also possible that AXOS improved the uptake of minerals in the caecum, as has been observed for inulin via lower $\mathrm{pH}$ caused by enhanced fermentation ${ }^{(104)}$. The production of butyrate, a fuel for the colonocytes, might have also improved the absorptive capacity of the intestinal mucosa ${ }^{(105)}$. Furthermore, these data indicated that AXOS modulated gut health by increasing bifidobacteria counts in line with observations in other animal models ${ }^{(106)}$; a benefit of bifidogenic effects is overall better gut health and thus better FCR. This observation perhaps suggested decreased energetic costs associated with constitutive low-level inflammation caused by enteropathogens or caused by reduced passage of pro-inflammatory components of (commensal) bacterial origin such as lipopolysaccharides $^{(107)}$. However, it remains to be proven that AXOS are released by xylanases in the GIT at levels sufficient to exert microbiota-modulating effects.

A potential limitation for in situ generation of AXOS via supplemental NSPases such as xylanase is the fact that xylanases are inhibited by the presence of AXOS (negative feedback), and the shorter the chain length the greater the inhibition, so in many cases the depolymerisation of xylan is self-limiting ${ }^{(108)}$, with the result that in situ production of AXOS in the gut might be limited. However, a recent study in rats indicated that the prebiotic potential and fermentation characteristics of cereal AXOS depend strongly on their structural properties ${ }^{(106)}$. The study reported that feeding a mixture of arabinoxylans of different DP (5-284) resulted in a larger increment in bifidobacteria in the caecum without increasing total bacteria; however, SCFA levels were greater for AXOS with 284 DP than for AXOS of 5 DP. Furthermore, evaluation of structurally different AXOS showed that smaller AXOS resulted in higher intestinal butyrate concentrations and a pronounced bifidogenic effect, whereas larger compounds mainly led to lower branched SCFA concentrations, an indication of lower proteolytic fermentation (i.e. better indices of gut health) ${ }^{(109)}$. These insights into the structure-activity relationship of AXOS suggest tremendous opportunity for developing and evolving FE products capable of in situ production of AXOS with optimised prebiotic and fermentation properties. Furthermore, perhaps future research could explore co-supplementation of NSPases/AXOS with probiotics to synchronise production of oligomers and utilisation.

Influence of feed enzymes on the gastrointestinal health-pathogen challenge: the case for a disease challenge model

Choct et al. ${ }^{(110)}$ reported that broiler chickens fed a wheatbased diet with xylanase had a negligible number of $C$. perfringens compared with control birds. Nian et al. ${ }^{(111)}$ showed that the addition of xylanase to a wheat-based diet improved performance and was accompanied by a reduction in the number of coliforms and Salmonella in the ileum. In piglets, there was a significant reduction in the frequency and severity of diarrhoea in piglets fed diets supplemented with fibre-degrading enzymes ${ }^{(112)}$. However, the cause of diarrhoea was not determined, which presents problems in interpreting these data, as the diarrhoea seen after weaning can be osmotic ${ }^{(15)}$ in nature rather than being of bacterial origin which might be influenced by $\mathrm{FE}^{(95)}$. The presence or absence of a pathogenic organism may not necessarily predict that disease will occur unless pathogen numbers proliferate to such an extent to overwhelm the normal microbial population in the GIT. However, the study of a specific bacterial disease, particularly if it causes economic loss, offers a means of assessing the usefulness of nutritional interventions or strategies on the survival of that particular pathogen in the GIT, and its subsequent effects on production, morbidity and mortality ${ }^{(15)}$.

There are a number of well-known enteric bacterial diseases that occur throughout the world, and each is relatively unique in that it generally occurs at different phases of pig and chicken growth and/or in different regions of the $\mathrm{GIT}^{(15,32)}$. Enteric diseases are an important concern to the poultry and pork industries because of production losses, increased mortality, reduced welfare of animals and increased risk of contamination of poultry and pork products for human consumption. Numerous reports have used experimental enteric pathogen challenge models to examine whether a particular feed additive or dietary strategy is effective in controlling pathogens under study ${ }^{(31,95)}$. A major advantage of using such an in vivo model is that the impact of the particular additive can be assessed in a context of an infectious pathogenic agent being part of the GIT ecosystem. The following sections deal with four enteric diseases that afflict chickens and pigs worldwide and report examples of investigations 
exploring how FE can modulate the expression of the pathogen and accompanying disease that can occur.

\section{Post-weaning colibacillosis in piglets}

Post-weaning colibacillosis is a disease largely afflicting the small intestine and is caused by certain enterotoxigenic strains of E. coli (ETEC). Despite a rapid digesta flow through the small intestine ${ }^{(113)}$, the pathogenic E. coli possess fimbriae, or pili, that attach to the enterocytes lining the small-intestinal villi or to the mucus covering the villi ${ }^{(23)}$. This attachment physically prevents the bacteria from being flushed through to the large intestine. E. coli fimbriae attach to glycoprotein receptors expressed in the brush border of cells lining the intestinal villi. The most common $E$. coli associated with causing post-weaning colibacillosis is $\mathrm{K} 88$, renamed as $\mathrm{F}^{(23)}$. After colonising the small intestine, ETEC provoke hypersecretory diarrhoea through the release of specific enterotoxins (heat-labile toxins) that cause secretion of ions and water into the lumen. Post-weaning colibacillosis is a major cause of mortality and morbidity worldwide ${ }^{(23)}$. Colonisation of the small intestine and diarrhoea usually lasts between 4 and $14 \mathrm{~d}$, with the strains being spread between animals primarily by the faecal-oral route, and also by aerosols ${ }^{(23)}$. However, it is important to note that despite ETEC being identified as the primary infectious agent in this disease, there is abundant evidence to suggest that a plethora of other factors are necessary for post-weaning colibacillosis to occur ${ }^{(23)}$. Given the economic importance of postweaning colibacillosis to pig production, diets fed to newly weaned pigs generally contain antimicrobial agents (antibiotics or $\mathrm{ZnO}$ ) to control post-weaning diarrhoea and reduce the negative impacts of this disease. Restriction on the use of antimicrobial agents in some parts of the world, however, has forced the pig industry to examine other ways of controlling this disease, with 'nutrition' being a prime and obvious area of investigation.

Thus, Kiarie et al. ${ }^{(114,115)}$ showed that when certain feedstuffs were incubated with a mixture of enzymes (xylanase, cellulases and mannanase) a wide range of sugars was released (Table 2). It is interesting to note that mannose was released during the hydrolysis of soyabean meal and wheat middlings; mannose is a well-described immune stimulant ${ }^{(116)}$. This indicated that when these ingredients were subjected to enzyme hydrolysis, potential exists for active prebiotic release. The potential of such enzyme hydrolysis products in influencing the secretory diarrhoea caused by ETEC K88 was assessed in an in situ model of secretory diarrhoea ${ }^{(117)}$. In this context, the enzyme hydrolysis products were infused into small-intestinal segments prepared in live anaesthetised pigs and experimentally infected with ETEC and fluid passage through the segments measured. The segments that were infused with soyabean, wheat or flaxseed hydrolysis products had greater fluid absorption than control segments that
Table 2. Monomeric sugar composition $(\mathrm{mg} / \mathrm{g})$ of enzyme hydrolysis products from common feedstuffs*

\begin{tabular}{lcccc}
\hline & \multicolumn{4}{c}{ Feed ingredient } \\
\cline { 2 - 5 } Sugar type & $\begin{array}{c}\text { Soyabean } \\
\text { meal }\end{array}$ & $\begin{array}{c}\text { Rapeseed } \\
\text { meal }\end{array}$ & $\begin{array}{c}\text { Wheat } \\
\text { middlings }\end{array}$ & $\begin{array}{c}\text { Flaxseed } \\
\text { meal }\end{array}$ \\
\hline Arabinose & 17.6 & 81 & 108 & 46 \\
Xylose & $2 \cdot 9$ & $39 \cdot 1$ & 208 & 196 \\
Mannose & 8.4 & nd & 7.9 & nd \\
Galactose & 129 & 25 & 15.5 & 69.2 \\
Glucose & $32 \cdot 8$ & 42.7 & 293 & 113.5 \\
\hline
\end{tabular}

nd, Not detected.

${ }^{*}$ Adapted from Kiarie et al. ${ }^{(114,115)}$.

were infused with an isotonic saline solution. What this means is that the hydrolysis products allowed the intestinal segments to retain more fluid and mitigate the negative effects of the ETEC infection. The fact that soyabean meal and wheat middlings had the greatest effects suggests that mannose mediated these effects, thus corroborating previous evidence that products derived from partial enzymic hydrolysis of wheat arabinoxylans ${ }^{(118)}$ and fermented soyabeans ${ }^{(119-121)}$ enhanced fluid and electrolyte balance in models of intestinal secretory diarrhoea.

The enzyme hydrolysis products were further tested in piglets fed either a control diet (devoid of ingredients used to generate the hydrolysis products) or a treatment diet with composite hydrolysis products from wheat middlings, soyabean meal, rapeseed meal and flaxseed at $5 \mathrm{~g} / \mathrm{kg}^{(122,123)}$. Piglets received these diets for $9 \mathrm{~d}$ during which basic performance metrics were measured. After this initial period, all pigs were orally challenged with ETEC and monitored for another $48 \mathrm{~h}$. During the prechallenge period piglets receiving diets with hydrolysis products ate more $(299$ v. $269 \mathrm{~g} / \mathrm{d})$ and grew faster $(252$ v. $207 \mathrm{~g} / \mathrm{d}$ ) than control piglets. Furthermore, during the challenge period, piglets fed hydrolysis products consumed more feed, suggesting the ability of enzyme hydrolysis products to attenuate ETEC enteritis, the hallmark of anorexia during infections (Fig. 3(A)). This peculiarity is explained by the lower incidence of diarrhoea (Fig. 3(B)) observed for the pigs fed the hydrolysis products. Interestingly, the piglets fed the enzyme hydrolysis products had lower stomach pH (2.62 v. 3.86) than the control piglets. Maintaining low gastric $\mathrm{pH}$ is important in the control of enteric pathogens such as ETEC which are transmitted within the herd via oral-faecal cycling ${ }^{(23)}$. The enzyme hydrolysis products mediated this effect by eliciting overall high fermentation as measured by increased organic acid production and in particular lactic acid concentration. Foregoing research indicates that enzyme hydrolysis products of common piglet feedstuffs were beneficial in minimising the negative effects of ETEC infection, affording the piglet a healthier gut as indicated by better appetite in the presence of active disease. It is relevant that viscous fibres have been linked with the exacerbation of colibacillosis in some studies ${ }^{(35,36)}$. 
(A)

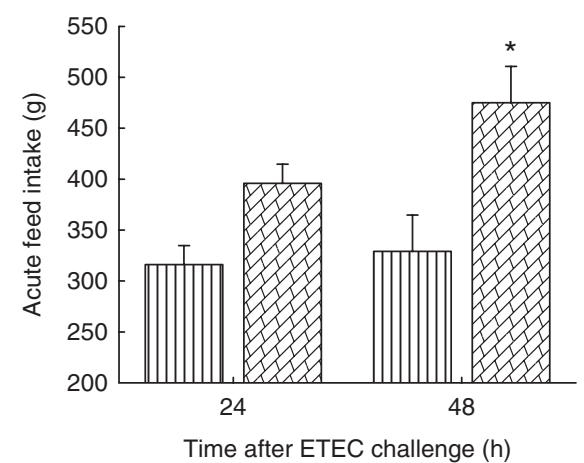

(B)

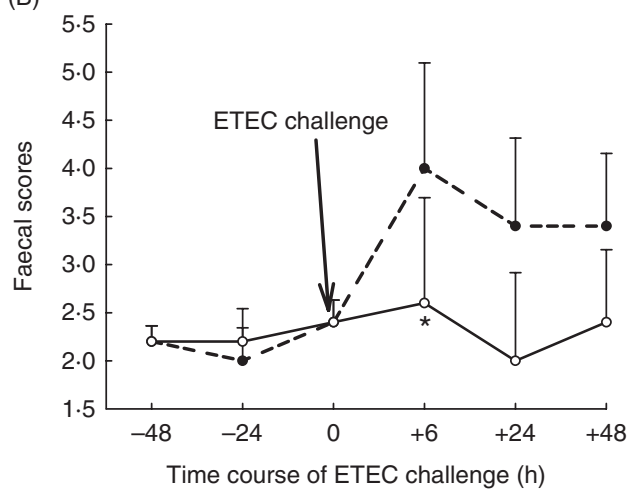

It appears that there is tremendous potential in developing FE for degrading NSP to generate short-chain oligosaccharides capable of controlling enteric infections such as ETEC-secretory diarrhoea.

\section{Swine dysentery}

$\mathrm{SD}$ is a mucohaemorrhagic colitis occurring mainly in growing-finishing pigs. It affects the caecum, colon and rectum and is caused by the anaerobic spirochaete Brachyspira (Serpulina) byodysenteriae ${ }^{(124)}$. Clinical manifestations vary considerably, but infected pigs typically develop diarrhoea, which initially is grey to black and sometimes watery, and progresses to consist of mucus plugs, fibrin, epithelial cell casts and flecks of fresh blood $^{(124)}$. In many countries, SD is one of the most economically important endemic bacterial diseases of swine during the grow-out period ${ }^{(15)}$. It is relevant that recent reports appear to indicate the emergence of SD in North America and anecdotal evidence appears to link this emergence to high usage of high-fibre co-products such as dried distillers grains with solubles ${ }^{(125)}$.

Many factors have been implicated in the aetiology of $\mathrm{SD}^{(124)}$ and there is compelling evidence that diet may modulate the expression of the disease. Numerous hypotheses have been advanced in an attempt to explain dietary effects on SD. These include dietary influence on the survival of spirochetes ${ }^{(126)}$, motility of the spirochete in the mucosal lining and chemotaxic-regulated motility ${ }^{(127)}$, ability of $B$. hyodysenteriae to express haemolysins and lipopolysaccharides that cause inflammation of the epithelium ${ }^{(128)}$. Pluske et al. ${ }^{(40)}$ showed that feeding a highly digestible diet based on cooked rice and high-quality proteins was more protective than a diet based on wheat, barley and sweet lupins. These authors surmised that a highly digestible diet reduced the degree of hindgut fermentation and reduced both the proliferation of B. byodysenteriae and clinical expression of the disease as opposed to wheat, barley and sweet lupins that promoted hindgut fermentation (as evidenced by lower $\mathrm{pH}$, increased SCFA levels, heavier organ weights). As alluded to, FE reduce the undigested components flowing into the hindgut and might also generate short-chain oligosaccharides that can modulate overall fermentation in the gut. It is therefore logical to expect that FE might partly modulate the expression of SD by reducing the load of fermentable substrate entering the large intestine.

This hypothesis was tested by Durmic et al. ${ }^{(38)}$ who fed extruded or non-extruded wheat without or with xylanase supplementation. Pigs were challenged with a virulent strain of B. byodysenteriae and subsequently monitored for expression of the disease. As expected, both extrusion of wheat and addition of xylanase increased pre-caecal starch digestion, as indicated by reduced starch levels in the large intestine. Furthermore, xylanase in non-extruded wheat improved growth performance, extending compelling evidence of the efficacy of xylanase in wheat-based diets. Xylanase increased microbiota activity and thus fermentation in the proximal areas of the hindgut, as corroborated by an increase in bacterial ATP concentrations. However, a peculiar observation in the study is the significant main effect of xylanase on digesta $\mathrm{pH}$ such that in the distal part of the colon, pigs fed xylanase had a higher $\mathrm{pH}$ than pigs not fed xylanase. These data suggested that xylanase accelerated the utilisation of carbohydrates in the proximal sections of the gut such that by the time the digesta reached the distal colon, $\mathrm{N}$ dominated as the fermentation substrate. An area that is not well researched is the impact of dietary protein and type and expression of $\mathrm{SD}^{(15)}$. Given the postulated effects of excess protein entering the caecum and colon on bacterial proliferation and production of bacterial metabolites ${ }^{(27)}$, it is feasible that this component of the diet might also influence the aetiology of SD. Perhaps an overall strategy should employ combination of NSPases and protease for synchronised carbohydrate and $\mathrm{N}$ disappearance in the upper gut. 
Furthermore, when assessing efficacy of FE in controlling $\mathrm{SD}$, it is important to recognise that bacterial species, such as Fusobacterium spp., Clostridium spp. and Bacteroides spp., need to be present in sufficient numbers for SD to occur ${ }^{(124)}$. It is therefore imperative for future studies to incorporate community profiling using $16 \mathrm{~S}$ rDNA sequence analysis to monitor potential inadvertent microbiome changes likely to implicate $\mathrm{FE}$ in B. byodysenteriae challenge studies.

\section{Salmonellosis}

Subclinical Salmonella enterica infections in pig herds and chicken flocks are recognised as important sources of human salmonellosis and hence a potential threat to human health through food-borne disease outbreaks ${ }^{(129)}$. Post-harvest measures are of importance to reduce the contamination of carcasses, but measures at the primary production site are still necessary to prevent transmission of Salmonella strains to the slaughterhouse. Although hygienic practices are important to avoid the introduction of Salmonella on the farm or reduce infection pressure when Salmonella is present, these practices do not sufficiently reduce Salmonella contamination on the farm. Feed additives constitute an important group of pre-harvest measures that can help in controlling Salmonella on the farm. Feed additives used for the control of Salmonella can be of different types, including antibiotics, prebiotics, probiotics and synbiotics ${ }^{(130)}$. An important role that feed additives can play is in reducing the infection pressure and thus limiting the risk of contamination of poultry and pork products. Among the non-antibiotic solutions, prebiotics have received much interest in controlling Salmonella infections in poultry ${ }^{(130)}$.

Eeckhaut et al. ${ }^{(131)}$ evaluated the influence of two AXOS differing in DP on shedding and colonisation of $S$. enteritidis in broilers upon challenge. The AXOS products were included in the control diet at $0 \cdot 2 \%$ for 3-DP-AXOS and $0.2 \%$ and $0.4 \%$ for 9-DP-AXOS. The AXOS attenuated Salmonella colonisation as shown by lower excreta shedding and concentration in the caecum tissues and systemic translocation to the spleen. This protection also seemed to be dose dependent, as the level of protection for all examined tissues was greater in the chicks receiving $0.4 \%$ 9-DP-AXOS compared with those receiving $0.2 \%$ of 9 -DP-AXOS. Furthermore, the average chain length appeared to play a role, because, in general, less Salmonella colonisation and translocation were observed with $0.2 \%$ 9-DP-AXOS than with the same dose of 3-DP-AXOS. These results were reproduced in birds fed xylanase and challenged with Salmonella ${ }^{(132)}$. These authors showed that the FCR of challenged birds fed xylanase was better than challenged control birds and commensurate with that of the non-challenged group. Interestingly, the responses were even greater when xylanase was fed in combination with a lactobacilli-based probiotic.
In a more recent Salmonella challenge study, Amerah et $a$. $^{\text {(133) }}$ showed that xylanase and essential oil supplementation reduced Salmonella-positive caecal samples in broiler chickens by 61 and $7 \cdot 7 \%$, respectively, compared with the control. Although combination xylanase and essential oil did not show synergistic benefits on influencing Salmonella colonisation, potential complementary effects of FE and additives such as essential oils and probiotics hold tremendous opportunity in controlling common enteric pathogens through reduced overall bacterial populations in the gut and the attendant benefit of decreased nutrient competition with the host and inflammatory pressure. Recent industry analysis revealed that Salmonella vaccination programmes have not consistently been able to prevent infection entirely (especially against high pathogen doses) or to effectively cross-protect against different serotypes ${ }^{(129)}$. It is therefore relevant that FE have the potential of complementing Salmonella vaccination programmes as a strategy for controlling pre-harvest salmonellosis in the poultry industry.

\section{Necrotic enteritis}

$\mathrm{NE}$ is considered one of the most threatening diseases in the broiler industry worldwide ${ }^{(32)}$. The total global economic loss as a consequence of NE outbreaks in broiler farms is estimated to be over US $\$ 2$ billion annually ${ }^{(134)}$. The causative agent of $\mathrm{NE}$ is $C$. perfringens, a Grampositive spore-forming anaerobe. In broilers, NE presents itself as a sudden increase in mortality occurring at any time when the birds are between 2 and 6 weeks old. Mortality may reach up to $1 \%$ perd and if left untreated may continue for $1-2$ weeks $^{(134)}$. In the last few years, a subclinical form of the disease has become more prevalent. It is characterised by poor digestion, reduced weight gain and increased FCR, without obvious increase in mortality $^{(32,134)}$. The hallmark of this disease is the presence of typical necrotic lesions particularly in the mid-region of the intestinal tract. Just like other enteric pathogens, many factors influence $C$. perfringens colonisation in the gut and subsequent expression of subclinical and clinical symptoms $^{(32,135)}$.

Gut ecology that favours growth of $C$. perfringens has been recognised as one of the key risk factors for the development of NE. In particular, the nature of the diet has been shown to be an important factor that influences the incidence of $\mathrm{NE}^{(32)}$; for example, diets with high levels of indigestible water-soluble $\mathrm{NSP}^{(30,31)}$. It is therefore relevant that the use of any additive such as FE that influences the digestibility and degradation of NSP may be useful in mitigating the proliferation of $C$. perfringens. This hypothesis was tested by Jia et al. ${ }^{(31)}$, who studied effects of diet type (maize $v$. wheat), multi-carbohydrase enzyme supplementation (without or with) and $C$. perfringens challenge (none and challenged) in broiler chickens. Growth performance, intestinal population of $C$. perfringens and gut 
lesions were among the responses evaluated. Birds fed maize-based diets had better FCR than those fed wheatbased diets. Pathogen challenge greatly impaired growth performance and increased intestinal $C$. perfringens counts and lesions. Enzyme supplementation minimised growth suppression associated with the pathogen challenge, with the most pronounced effect observed in birds fed the wheat-based diet. Instructively, wheat-based diets were observed to have induced high jejunal digesta viscosity that was reduced by enzyme addition. Similarly, an earlier study by Riddell \& Kong ${ }^{(29)}$ observed mortality due to NE to be higher among broiler chickens fed rations based on wheat, rye, barley and oats than among chickens fed maize-based rations upon challenge with $C$. perfringens. However, these authors could not find any beneficial effect of xylanase supplementation on the susceptibility to NE in broilers fed wheat-based diets.

An important factor worth considering in reproducing $\mathrm{NE}$ in an experimental challenge with $C$. perfringens is that there is compelling evidence that $C$. perfringens and Eimeria spp. act synergistically in inducing NE lesions. In this context, co-infection with $C$. perfringens and Eimeria oocysts or an overdose of commercial coccidiosis vaccines containing attenuated Eimeria strains has been shown to result in more birds with lesions or in higher mortality rates compared with birds receiving only Eimeria or only C. perfringens ${ }^{(32,135)}$. The peculiarity is that Eimeria parasites kill intestinal epithelial cells as a consequence of the intracellular stages of their lifecycle ${ }^{(135)}$. As a consequence, plasma proteins leak into the gut lumen through the resulting gaps in the epithelial lining of the intestinal lumen, and these serve as a growth substrate for $C$. perfringens strains $^{(134,135)}$. It is also likely that the resulting malabsorption of nutrients due to the damage in the intestinal lining increases substrates for pathogen growth. Moreover, coccidial infection induces a T-cell-mediated inflammatory response that enhances intestinal mucogenesis ${ }^{(135)}$. This enhanced mucin production provides a growth advantage to $C$. perfringens due to its ability to use mucus as a substrate ${ }^{(74,136)}$. In view of the foregoing and for the purpose of clarity in data interpretation, it is imperative to assess the effect of $\mathrm{FE}$ in modulating $C$. perfringens challenge within a context of a commercial coccidiosis vaccine. For example, Jackson et al. ${ }^{(137)}$ used a NE disease challenge model involving oral inoculation of Eimeria spp. and C. perfringens and reported that $\beta$-mannanase was as effective as antibiotics in mitigating the disease effects as measured by growth performance and the incidence of coccidial lesion scores compared with the control. This study suggests that FE can play a role in controlling NE in circumstances where the use of antibiotics is not desired.

\section{A core microbiome at a functional level}

Reduction of undigested substrates in the small intestine and provision of fermentable NSP hydrolysis products are perhaps the probable means by which FE can affect gut microbiota. This is more so in instances where antinutrients such as phytic acids and viscous ingredients attenuate digestion such that significant quantities of starch and/or protein enter the large intestine, stimulating the activity of putrefactive bacteria and pre-disposing the animal to intestinal disorders. Clearly, under such circumstances the use of FE will improve small intestine digestion and as a result limit substrate availability in the large intestine, effectively mitigating any potential GIT microbial dysfunction $^{(31,38,112)}$. However, it is still unclear whether, on feeding FE, the shifts in microbial profiles in the hindgut have a greater impact on animal health and nutrition than shifts in ileal profiles. Indeed, in some cases there may be significant changes in hindgut or ileal microbial profiles with little or no associated response in performance, indicating that the two are not always linked ${ }^{(138)}$ Nevertheless, it is clear that the response of the microflora to FE probably depends on the initial GIT microbial status, which in turn depends on the form and digestibility of the diet and the extent of the microfloral challenge it evokes. Many of the factors governing the extent of FE responses are most probably similar to those influencing responses to in-feed antimicrobials. For example, the response to antimicrobials in the diet depends to a large degree on the conditions under which the animals are raised ${ }^{(13,58)}$. It is likely that any positive responses to FE will be dictated not only by the status of the microflora in the GIT, but also by environmental, management and dietary factors such as cereal type and quality, and processing ${ }^{(3,139)}$.

By fair estimation most pigs and chickens are fed mostly non-viscous maize-based diets; furthermore, quite a great deal of advances have been made in housing equipment and bio-security. Under such production systems it might be difficult for a nutritionist to economically justify an extra dose of FE to cater for gut health. However, a key metric for profitability in swine and poultry production is growth performance, which in turn is dependent on variability in animal health and efficient utilisation of feed. At times this variability is driven by genetics and it is therefore likely that responses to FE may also depend upon the genotype of the animal. For example, Garcia et al. ${ }^{(140)}$ observed that xylanase use in birds selected over five generations for divergent digestion efficiency attenuated bile acid deconjugation (a measure of deleterious microbiota in the small intestines) in the less but not in the more efficient birds. But even so, when similar genotypes are fed the same diets variability in performance is expected and is indeed a major challenge for production systems employing all-in and all-out flock or herd flow management.

FE have a role in increasing uniformity of the flock or herd and thus improving profitability. However, the application of FE to manage poor-performing animals in a herd or flock would perhaps be more precise if such variability impinges on gut microbiota. Indeed, there is 
growing evidence linking dietary nutrient utilisation, growth performance and GIT microbiota composition $^{(17,53,141)}$. Classical work by Turnbugh et al. ${ }^{(142)}$ demonstrated that a diversity of GIT microbiota assemblages can yield a core microbiome at a functional level, and that deviations from this core are associated with different physiological states (obese $v$. lean). This study corroborated earlier findings in mice by Turnbaugh et $a l^{(143)}$ and collectively demonstrates that the microbiomes in obese mice and human individuals harbour a larger proportion of genes for digesting fat, protein and carbohydrates, which might make them better at extracting and storing energy from food. As the application of molecular microbiology techniques increases in animal nutrition research, a potential strategy can be the establishment of robust and repeatable associations between enrichment of particular strains or clusters of bacteria and animal performance. In this context, recent studies by Torok et $a l^{(17,53)}$ linking poorly performing and wellperforming broilers to distinct GIT microbiome is a step in the right direction. It may be possible to evolve and develop FE to induce desirable changes in the gut microbiota for the enhancement of growth and uniformity of the production of commercial herds and flocks.

In studies involving microbial community analysis, the complexity of interpretation increases with the use of molecular techniques, all of which are subject to potential pitfalls of PCR and other limitations ${ }^{(144,145)}$. No method is ideal, and even with the most advanced PCR-based techniques it is possible that microbial groups representing a significant fraction of the total microbial community escape detection. Consequently, it is possible that a link between microbiota and performance can be found using one method but not confirmed using some other method, even if the trial setup is identical ${ }^{(141)}$. Understanding the dynamics of the gut microbial community, or microbial balance, is necessary to establish or develop strategies to improve feed efficiency and growth rate, avoid intestinal diseases and proliferation of food-borne pathogens, and evolve efficacious FE systems. Undoubtedly, molecular microbiology techniques are an important strategy in such endeavours. The $16 \mathrm{~S}$ rRNA gene sequences generated in various studies could be used as a basis for developing quantitative assays and thus allowing validation of the presence of performance-related gut bacteria; potentially, these assays could be used to monitor strategies to improve feed efficiency ${ }^{(17)}$. Such advances will probably be slow but ultimately optimal and detrimental microbial populations should be easily quantified and strategies to avert disease and poor performance more easily formulated ${ }^{(141)}$.

\section{Conclusions}

Although research on application of FE to modulate animal gut health is still in its infancy, the implications in terms of economic savings and its potential as an alternative technology to replace antibiotic growth promoters in pig and poultry feeding programmes are significant. Growing scientific evidence suggests that FE can be part of an integrated solution approach for containing enteric pathogens of economic importance. This value is not only captured in reduced medication costs, but also in a reduced variability in animal performance and reduced mortality by promoting gut health. Any additive, such as FE, which influences the digestibility of the diet will change the selection pressures on the microbiota which in turn will moderate the efficiency with which the host utilises its feed, and the immune interactions with the intestinal microbiome. However, the response of the microbiome to enzyme addition probably depends on the microbial status of the production system. Because FE are likely to change substrate characteristics (for example, release of xylooligosaccharides) and flow along the GIT, the subsequent microbiota responses will vary according to the populations present at the time of administration and their reaction to such changes, as well as the immune status of the animals and the presence of stress factors. It is not surprising that given the huge range of microbiota conditions likely to exist between studies, the responses to FE use, rather than being absolute, are a continuum or a population of responses. Nonetheless, recognition that FE can make an impact on the GIT microbiota and thus gut health will stimulate development of FE capable of modulating GIT microbiota to the benefit of host health under specific production conditions. The role of FE as part of an integral approach to animal health that is less reliant on antibiotic compounds appears to be important, although more research is needed to further elucidate factors affecting host-microbiome-diet interactions, and the strategies to alter those interactions in favour of the host.

\section{Acknowledgements}

E. K, L. F. R. and C. M. N. searched the literature, discussed and agreed on the review content, and wrote the paper; E. K. had primary responsibility for final content. All authors read and approved the final manuscript. This research did not receive specific grants from any funding agency in the public, commercial or not-for-profit sectors. E. K. and L. F. R. are employees of a feed additives supplier.

The authors do not have any conflict of interests.

\section{References}

1. Bailey JE \& Olis DF (1986) Biochemical Engineering Fundamentals, 2nd ed. NY: McGraw Hill Publishing Company.

2. Mitchell DA \& Lonsane BK (1992) Definition, characteristics and potential. In Solid Substrate Cultivation, pp. 1-13 [HW Doelle, DA Mitchell and CE Rolz, editors]. New York: Elsevier Applied Biotechnology Series. 
3. Adeola O \& Cowieson AJ (2011) Opportunities and challenges in using exogenous enzymes to improve non-ruminant animal production. J Anim Sci 89, 3189-3218.

4. Barletta A (2010) Introduction: current markets and expected development. In Enzymes in Farm Animal Nutrition, 2nd ed., pp. 1-11 [MR Bedford and GG Partridge, editors]. Wallingford, UK: CAB International.

5. Bedford MR \& Schulze H (1998) Exogenous enzymes for pigs and poultry. Nutr Res Rev 11, 91-114.

6. Woyengo TA \& Nyachoti CM (2011) Review: Supplementation of phytase and carbohydrases to diets for poultry. Can J Anim Sci 91, 177-192.

7. Slominski BA (2011) Recent advances in research on enzymes for poultry diets. Poult Sci 90, 2013-2023.

8. Kiarie E \& Nyachoti CM (2009) Alternative feed ingredients in swine diets. In Proceedings of the 32nd Saskatchewan Pork Industry Symposium, pp. 29-38. Saskatoon: Saskatchewan Pork Development Board.

9. Bach Knudsen KE (2011) Effects of polymeric carbohydrates on growth and development in pigs. J Anim Sci 89, 1965-1980.

10. Bedford MR \& Partridge GG (2010) Feed enzymes, the future: bright hope or regulatory mine field? In Enzymes in Farm Animal Nutrition, 2nd ed., pp. 304-312 [MR Bedford and GG Partridge, editors]. Wallingford, UK: CAB International.

11. Savage DC (1977) Microbial ecology of the gastrointestinal tract. Annu Rev Microbiol 31, 107-133.

12. Jensen BB (1998) The impact of feed additives on the microbial ecology of the gut in young pigs. J Anim Feed Sci 7, 45-64.

13. Gaskins HR (2001) Intestinal bacteria and their influence on swine growth. In Swine Nutrition, 2nd ed., pp. 585-608 [AJ Lewis and LL Southern, editors]. Boca Roca, FL: Taylor and Francis Inc.

14. Gong J, Si W, Forster RJ, et al. (2007) 16S rRNA gene-based analysis of mucosa-associated bacterial community and phylogeny in the chicken gastrointestinal tracts; from crops to ceca. FEMS Microbiol Ecol 59, 147-157.

15. Pluske JR, Pethick DW, Hopwood DE, et al. (2002) Nutritional influences on some major enteric bacterial diseases of pigs. Nutr Res Rev 15, 333-371.

16. Zoetendal EG, Collier CT, Koike S, et al. (2004) Molecular ecological analysis of the gastrointestinal microbiota: a review. J Nutr 134, 465-472.

17. Torok VA, Hughes RJ, Mikkelsen LL, et al. (2011) Identification and characterization of potential performancerelated gut microbiota in broiler chickens across various feeding trials. Appl Environ Microbiol 77, 5868-5878.

18. Danzeisen JL, Kim HB, Isaacson RE, et al. (2011) Modulations of the chicken cecal microbiome and metagenome in response to anticoccidial and growth promoter treatment. PLOS One 6, e27949.

19. Kim HB, Borewicz K, White BA, et al. (2011) Longitudinal investigation of the age-related bacterial diversity in the feces of commercial pigs. Vet Microbiol 153, 124-133.

20. Stanley D, Geier MS, Hughes RJ, et al. (2012) The role of gastrointestinal tract microbiota in chicken productivity. Proc Aust Poult Sci Symp 23, 262-265.

21. Klasing KC (2007) Nutrition and the immune system. Br Poult Sci 8, 525-537.

22. Niba AT, Beal JD, Kudi AC, et al. (2009) Bacterial fermentation in the gastrointestinal tract of non-ruminants: influence of fermented feeds and fermentable carbohydrates. Trop Anim Health Prod 41, 1393-1407.

23. Fairbrother JM, Nadeau É \& Gyles GL (2005) Escherichia coli in post-weaning diarrhea in pigs: an update on bacterial types, pathogenesis, and prevention strategies. Anim Health Res Rev 6, 17-39.

24. Hillman K (2004) An analysis of gut microbes. Pig Int 34, 27-29.

25. Mackie RI \& White BA (1997) Gastrointestinal Microbiology. New York: Chapman and Hall.

26. de Lange CFM, Pluske J, Gong J, et al. (2010) Strategic use of feed ingredients and feed additives to stimulate gut health and development in young pigs. Livest Sci 134, 124-134.

27. Heo JM, Opapeju FO, Pluske JR, et al. (2013) Gastrointestinal health and function in weaned pigs: a review of feeding strategies to control post-weaning diarrhea without using in-feed antimicrobial compounds. J Anim Physiol Anim Nutr (Berl) 97, 207-237.

28. Adjiri-Awere A \& Van Lunen TA (2005) Subtherapeutic use of antibiotics in pork production: risks and alternatives. Can J Anim Sci 85, 117-130.

29. Riddell C \& Kong XM (1992) The influence of diet on necrotic enteritis in broiler chickens. Avian Dis 36, 499-503.

30. Kaldhusdal M \& Skjerve E (1996) Association between cereal contents in the diet and incidence of necrotic enteritis in broiler chickens in Norway. Prev Vet Med 28, 1-16.

31. Jia W, Slominski BA, Bruce HL, et al. (2009) Effect of diet type and enzyme addition on growth performance and gut health of broiler chickens during subclinical Clostridium perfringens challenge. Poult Sci 88, 132-140.

32. Timbermont L, Haesebrouck F, Ducatelle R, et al. (2011) Necrotic enteritis in broilers: an updated review on the pathogenesis. Avian Pathol 40, 341-347.

33. McDonald DE, Pethick DW, Pluske JR, et al. (1999) Adverse effects of soluble non-starch polysaccharide (guar gum) on piglet growth and experimental colibacillosis immediately after weaning. Res Vet Sci 67, 245-250.

34. McDonald DE, Pethick DW, Mullan BP, et al. (2001) Increasing viscosity of the intestinal contents alters small intestinal structure and intestinal growth, and stimulates proliferation of enterotoxigenic Escherichia coli in newly-weaned pigs. Br J Nutr 86, 487-498.

35. Hopwood DE, Pethick DE, Pluske JR, et al. (2004) Addition of pearl barley to a rice-based diet increases the viscosity of the intestinal contents, reduces starch digestibility and exacerbates post-weaning colibacillosis in piglets. $\mathrm{Br} J$ Nutr 92, 419-427.

36. Montagne L, Cavaney FS, Hampson DJ, et al. (2004) Effect of diet composition on postweaning colibacillosis in piglets. J Anim Sci 82, 2364-2374.

37. Durmic Z, Pethick DW, Pluske JR, et al. (1998) Influence of dietary fibre sources and levels of inclusion on the colonic microbiota of pigs, and on the development of swine dysentery in experimentally-infected pigs. J Appl Microbiol $\mathbf{8 5}$ 574-582.

38. Durmic Z, Pethick DW, Mullan BP, et al (1997) The effects of extrusion and arabinoxylanase in wheat based diets on fermentation in the large intestine and expression of swine dysentery. In Manipulating Pig Production VI, p. 180 [PD Cranwell, editor]. Canberra: Australasian Pig Science Association.

39. Pluske JR, Siba PM, Pethick DW, et al. (1996) The incidence of swine dysentery in pigs can be reduced by feeding diets that limit the amount of fermentable substrate entering the large intestine. J Nutr 126, 2920-2933.

40. Pluske JR, Durmic Z, Pethick DW, et al. (1998) Confirmation of the role of rapidly fermentable carbohydrates in the expression of swine dysentery in pigs after experimental infection. J Nutr 128, 1737-1744.

41. Smulders ACJM, Veldman A \& Enting H (1999) Effect of anti-microbial growth promoter in feeds with different 
levels of indigestible protein on broiler performance. In Proceedings of the 12th European Symposium on Poultry Nutrition, pp. 177-182. Veldhaven, The Netherlands: World Poultry Science Association (Dutch Branch).

42. Cone JW, Jongbloed AW, Van Gelder AH, et al. (2005) Estimation of protein fermentation in the large intestine of pigs using a gas production technique. Anim Feed Sci Technol 124, 463-472.

43. Marquardt RR, Ward AT \& Misir R (1979) The retention of nutrients by chicks fed rye diets supplemented with amino acids and penicillin. Poult Sci 58, 631-640.

44. Antoniou TC \& Marquardt RR (1982) Utilization of rye diets by chicks as affected by lipid type and level and penicillin supplementation. Poult Sci 61, 107-116.

45. Choct M, Hughes RJ, Wang J, et al. (1996) Increased small intestinal fermentation is partly responsible for the antinutritive activity of non-starch polysaccharides in chickens. Br Poult Sci 37, 609-621.

46. Almirall M, Francesch M, Perez-Vendrell AM, et al. (1995) The differences in intestinal viscosity produced by barley and $\beta$-glucanase after digesta enzyme activities and ileal nutrient digestibility more in broiler chicks than in cocks. J Nutr 125, 947-955.

47. Gee JM, Lee-Finglas W, Wortley GW, et al. (1996) Fermentable carbohydrates elevate plasma enteroglucagon but high viscosity is also necessary to stimulate small bowel mucosal cell proliferation in rats. J Nutr 126, 373-379.

48. Teirlynck E, Bjerrum L, Eeckhaut V, et al. (2009) The cereal type in feed influences gut wall morphology and intestinal immune cell infiltration in broiler chickens. BrJ Nutr $\mathbf{1 0 2}$, 1453-1461.

49. Daenicke S, Bottcher W, Jeroch H, et al. (2000) Replacement of soybean oil with tallow in rye-based diets without xylanase increases protein synthesis in small intestine of broilers. J Nutr 130, 827-834.

50. Fernandez F, Sharma R, Hinton M, et al. (2000) Diet influences the colonization of Campylobacter jejuni and distribution of mucin carbohydrates in the chick intestinal tract. Cell Mol Life Sci 5, 1793-1801.

51. Jørgensen H, Zhao X-Q \& Eggum BO (1996) The influence of dietary fibre and environmental temperature on the development of the gastrointestinal tract digestibility degree of fermentation in the hind-gut and energy metabolism in pigs. Br J Nutr 75, 365-378.

52. Hübener K, Vahjen W \& Simon O (2002) Bacterial responses to different dietary cereal types and xylanase supplementation in the intestine of broiler chicken. Arch Anim Nutr 56, 167-187.

53. Torok VA, Ophel-Keller K, Loo M, et al. (2008) Application of methods for identifying broiler chicken gut bacterial species linked with increased energy metabolism. Appl Environ Microbiol 74, 783-791.

54. Zhang C, Zhang M, Wang S, et al. (2010) Interactions between gut microbiota, host genetics and diet relevant to development of metabolic syndromes in mice. ISME J 4, 232-241.

55. Chen KT, Malo MS, Moss AK, et al. (2010) Identification of specific targets for the gut mucosal defense factor intestinal alkaline phosphatase. Am J Physiol Gastrointest Liver Physiol 299, G467-G475.

56. Lallés J-P (2010) Intestinal alkaline phosphatase: multiple biological roles in maintenance of intestinal homeostasis and modulation by diet. Nutr Rev 68, 323-332.

57. Visek WJ (1978) The mode of growth promotion by antibiotics. J Anim Sci 46, 1447-1469.

58. Niewold TA (2007) The non-antibiotic anti-inflammatory effect of antimicrobial growth promoters, the real mode of action? A hypothesis. Poult Sci 86, 605-609.
59. Apajalahti J, Kettunnen A \& Graham H (2004) Characteristics of the gastrointestinal microbial communities, with special reference to the chicken. World Poult Sci J 60, 223-232.

60. Drew MD, Van Kessel AG, Estrada AE, et al. (2002) Effect of dietary cereal on intestinal bacterial populations in weaned pigs. Can J Anim Sci 82, 607-609.

61. Bird AR, Vuaran M, Brown I, et al. (2007) Two high-amylose maize starches with different amounts of resistant starch vary in their effects on fermentation, tissue and digesta mass accretion, and bacterial populations in the large bowel of pigs. BrJ Nutr 97, 134-144.

62. Regmi PR, Metzler-Zebeli BU, Gänzle MG, et al. (2011) Starch with high amylose content and low in vitro digestibility increases intestinal nutrient flow and microbial fermentation and selectively promotes bifidobacteria in pigs. J Nutr 141, 1273-1280.

63. Ferrell CL (1988) Contribution of visceral organs to animal energy expenditures. J Anim Sci 66, 23-34.

64. Agyekum AK, Slominski BA \& Nyachoti CM (2012) Organ weight, intestinal morphology, and fasting whole-body oxygen consumption in growing pigs fed diets containing distillers dried grains with solubles alone or in combination with a multi-enzyme supplement. J Anim Sci 90, 3032-3040.

65. Kiarie E \& Nyachoti CM (2009) Bioavailability of calcium and phosphorous in feedstuffs for farm animals. In Phosphorous and Calcium Utilization and Requirements in Farm Animals, pp. 76-83 [DMSS Vitti and E Kebreab, editors]. Wallingford: CAB International.

66. Selle PH \& Ravindran V (2007) Microbial phytase in poultry nutrition. Anim Feed Sci Technol 135, 1-41.

67. Selle PH \& Ravindran V (2008) Phytate-degrading enzymes in pig nutrition. Livest Sci 113, 99-122.

68. Selle PH, Cowieson AJ, Cowieson NP, et al. (2012) Protein-phytate interactions in pig and poultry nutrition: a reappraisal. Nutr Res Rev 25, 1-17.

69. Cowieson AJ, Acamovic T \& Bedford MR (2004) The effects of phytase and phytic acid on the loss of endogenous amino acids and minerals from broiler chickens. Br Poult Sci 45, 101-108.

70. Adedokun SA, Adeola O, Parsons CM, et al. (2011) Factors affecting endogenous amino acid flow in chickens and the need for consistency in methodology. Poult Sci 90, 1737-1748.

71. Onyango EM, Asem KE \& Adeola O (2009) Phytic acid increases mucin and endogenous amino acid losses from the gastrointestinal tract of chickens. BrJ Nutr 101, 836-842.

72. Yu S, Cowieson AJ, Gilbert C, et al. (2012) Interactions of phytate and myo-inositol phosphate esters (IP1-5) including IP5 isomers with dietary protein and iron and inhibition of pepsin. J Anim Sci 90, 1824-1832.

73. Lumpkins BS, Humphrey B, Mathis G, et al. (2009) Performance, nutrient digestibility and expression of intestinal mucin RNA of 21 day old broiler chickens supplemented with 5000 FTU of phytase. Poult Sci $\mathbf{8 8}$, Suppl. 1, 59 (abstract).

74. Cooper KK \& Songer J (2009) Necrotic enteritis in chickens: a paradigm of enteric infection by Clostridium perfringens type A. Anaerobe 15, 55-60.

75. Smulikowska S, Czerwinski J \& Mieczkowska A (2010) Effect of an organic acid blend and phytase added to a rapeseed cake containing diet on performance, intestinal morphology, caecal microfloral activity and thyroid status of broiler chickens. J Anim Physiol Anim Nutr 94, 15-23.

76. Metzler-Zebeli BU, Vahjen W, Baumgartel T, et al. (2010) Ileal microbiota of growing pigs fed different calcium phosphate levels and phytase content and subjected to ileal pectin infusion. J Anim Sci 88, 147-158. 
77. Wang L \& Lei XG (2011) Supplemental dietary phytase alters gut microbiota of weanling pigs. J Anim Sci 89, ESuppl. 1, 187 (abstract).

78. Rostagno MH, Ferrel J, Radcliffe JS, et al. (2012) Dietary supplementation with alkaline phosphatase affects intestinal microbial populations of nursery pigs. In Proccedings of the XII International Symposium on Digestive Physiology of Pigs, Keystone Resort and Conference Center, Keystone, CO, pp. 45-46

79. Doerrler WT (2006) Lipid trafficking to the outer membrane of Gram-negative bacteria. Mol Microbiol 60, 542-552.

80. Malo MS, Alam SN, Mostafa G, et al. (2010) Intestinal alkaline phosphatase preserves the normal homeostasis of gut microbiota. Gut 59, 1476-1484.

81. Romero LF \& Plumstead PW (2011) Starch, protein and fat digestibility as predictors of enzyme responses in broiler diets. AFMA Matrix 20, 12-17.

82. Romero LF, Plumstead PW \& Ravindran V (2011) Energy contribution of digestible starch, fat, and protein in response to combinations of exogenous xylanase, amylase, and protease in corn-based broiler diets. Poult Sci 90, ESuppl. 1, 20, (abstract).

83. Hampson DJ, Phillips ND \& Pluske JR (2002) Dietary enzyme and zinc bacitracin reduce colonisation of layer hens by the intestinal spirochaete Brachyspira intermedia. Vet Microbiol 86, 351-360.

84. Simon O (1998) The mode of action of NSP hydrolyzing enzymes in the gastrointestinal tract. J Anim Feed Sci 7, $115-123$.

85. Castanon JIR, Flores MP \& Pattersson D (1997) Mode of degradation of non-starch polysaccharides by feed enzyme preparations. Anim Feed Sci Technol 68, 361-365.

86. Meng X (2005) Improved nutrient utilization and growth performance of broiler chickens fed diets supplemented with multi-carbohydrase enzyme preparations. PhD thesis, University of Manitoba

87. Voragen AGJ (1998) Technological aspects of functional food-related carbohydrates. Food Sci Technol 9, 328-335.

88. Vázquez MJ, Alonso JL, Domínguez H, et al. (2000) Xylooligosaccharides: manufacture and applications. Trends in Food Sci Technol 11, 387-393.

89. Chesson A \& Stewart CS (2001) Modulation of the gut microflora by enzyme addition. In Gut Environment of Pigs, pp. 165-179 [A Piva, KE Bach Knudsen and J-E Lindberg, editors]. Loughborough: Nottingham University Press.

90. Sunna A \& Antranikian G (1997) Xylanolytic enzymes from fungi and bacteria. Crit Rev Biotechnol 17, 39-67.

91. Hespell RB, O’Bryan PJ, Moniruzzaman M, et al. (1997) Hydrolysis by commercial enzyme mixtures of AFEX-treated corn fiber and isolated xylans. Appl Biochem Biotechnol 62, $87-97$.

92. Li K, Azadi P, Collins R, et al. (2000) Relationships between activities of xylanases and xylan structure. Enzyme Microbiol Technol 27, 89-94.

93. Austin SC, Wiseman J \& Chesson A (1999) Influence of non-starch polysaccharide structure on the metabolizable energy of UK wheat fed to poultry. J Cereal Sci 29, 77-88.

94. Apajalahti J \& Bedford M (1998) Nutrition effects on the microflora of the GI tract. In Proceedings of the 19th Western Nutrition Conference, pp. 60-68. Saskatoon: University of Saskachewan.

95. Kiarie E (2008) Dietary means for enhanced gastrointestinal health and function in weaned pigs: an evaluation of carbohydrase enzymes targeting non-starch polysaccharides. PhD thesis, University of Manitoba

96. Diebold G, Mosenthin R, Piepho HP, et al. (2004) Effect of supplementation of xylanase and phospholipase to a wheatbased diet for weanling pigs on nutrient digestibility and concentrations of microbial metabolites in ileal digesta and feces. J Anim Sci 82, 2647-2656.

97. Osswald T, Vahjen W \& Simon O (2006) Influence of different non starch polysaccharide degrading feed enzymes on the intestinal microbiota in piglets. Slovak J Anim Sci 39, 55-58.

98. Kiarie E, Nyachoti CM, Slominski BA, et al. (2007) Growth performance, gastrointestinal microbial activity, and nutrient digestibility in early-weaned pigs fed diets containing flaxseed and carbohydrase enzyme. J Anim Sci 85, 2982-2993.

99. Rosin EA, Blank G, Slominski BA, et al. (2007) Enzyme supplements in broiler chicken diets: in vitro and in vivo effects on bacterial growth. J Sci Food Agric 87, 1009-1020.

100. Jòzefiak DA, Rutkowski S, Kaczmarek BB, et al. (2010) Effect of $\beta$-glucanase and xylanase supplementation of barley- and rye-based diets on cecal microbiota of broiler chickens. Br Poult Sci 51, 546-557.

101. Choct M, Hughes RJ \& Bedford MR (1999) Effects of a xylanase on individual bird variation, starch digestion throughout the intestine, and ileal and cecal volatile fatty acid production in chickens fed wheat. Br Poult Sci 40, 419-422.

102. Courtin CM, Broekaert WF, Swennen K, et al. (2008) Dietary inclusion of wheat bran arabinoxylooligosaccharides induces beneficial nutritional effects in chickens. Cereal Chem 85, 607-613.

103. Bach Knudsen KE (1997) Carbohydrate and lignin contents of plant materials used in animal feeding. Anim Feed Sci Technol 67, 319-338.

104. Van Loo JAE (2004) Prebiotics promote good health. The basis, the potential, and the emerging evidence. I Clin Gastroenterol 38, S70-S75.

105. Guilloteau P, Martin L, Eeckhaut V, et al. (2010) From the gut to the peripheral tissues: the multiple effects of butyrate. Nutr Res Rev 23, 366-384.

106. Damen B, Verspreet J, Pollet A, et al. (2011) Prebiotic effects and intestinal fermentation of cereal arabinoxylans and arabinoxylan oligosaccharides in rats depend strongly on their structural properties and joint presence. Mol Nutr Food Res 55, 1862-1874.

107. Anderson DB, McCracken VJ, Aminov RI, et al. (2000) Gut microbiology and growth-promoting antibiotics in swine. Nutr Abstr Rev Series B: Livest Feeds and Feeding 70, 101-108.

108. Lo LL \& Pickersgill RW (1999) Xylanase-oligosaccharide interactions studied by a competitive enzyme assay. Enzyme Microbiol Technol 25, 701-709.

109. Van Craeyveld V, Swennen K, Dornez E, et al. (2008) Structurally different wheat-derived arabinoxylooligosaccharides have different prebiotic and fermentation properties in rats. $J$ Nutr 138, 2348-2355.

110. Choct M, Sinlae M, Al-Jassim RAM, et al. (2006) Effects of xylanase supplementation on between-bird variation in energy metabolism and the number of Clostridium perfringens in broilers fed a wheat-based diet. Aust J Agric Res 57, 1017-1021.

111. Nian F, Guo YM, Ru YJ, et al. (2011) Effect of xylanase supplementation on the net energy for production, performance and gut microflora of broilers fed corn/soy-based diet. Asian-Aust J Anim Sci 24, 1282-1287.

112. Inborr J \& Ogle RB (1988) Effect of enzyme treatment of piglet feeds on performance and post weaning diarrhea. Swedish J Agric Res 8, 129-133.

113. Turlington WH, Allee GL \& Nelssen JL (1989) Effects of protein and carbohydrate sources on digestibility and digesta flow rate in weaned pigs fed a high-fat, dry diet. J Anim Sci 67, 2333-2340. 
114. Kiarie E, Slominski BA, Krause DO, et al. (2008) Non-starch polysaccharide hydrolysis products of soybean and canola meal protect against enterotoxigenic Escherichia coli in piglets. J Nutr 138, 502-508.

115. Kiarie E, Slominski BA \& Nyachoti CM (2010) Effect of products derived from hydrolysis of wheat and flaxseed non starch polysaccharides by carbohydrase enzymes on net absorption in enterotoxigenic Escherichia coli (K88) challenged piglet jejunal segments. Anim Sci J 81, 63-71.

116. Jensen GS, Patterson KM \& Yoon I (2008) Yeast culture has anti-inflammatory effects and specifically activates NK cells. Comp Immunol Microbiol Infect Dis 31, 487-500.

117. Nabuurs MJ, Hoogendoorn A, van Zijderveld FG, et al. (1993) A long-term perfusion test to measure net absorption in the small intestine of weaned pigs. Res Vet Sci 55 , $108-114$.

118. Alam N, Sarker SA, Molla AM, et al. (1987) Hydrolyzed wheat based oral rehydration solution for acute diarrhea. Arch Dis Child 62, 440-444.

119. Kiers JL, Meijer JC, Nout MJR, et al. (2003) Effect of fermented soybeans on diarrhea and feed efficiency in weaned piglets. J Appl Microbiol 95, 545-552.

120. Kiers JL, Nout MJR, Rombouts FM, et al. (2006) Effect of processed and fermented soybeans on net absorption in enterotoxigenic Escherichia coli-infected piglet small intestine. Br J Nutr 95, 1193-1198.

121. Kiers JL, Nout MJR, Rombouts FM, et al. (2007) A high molecular weight soluble fraction of tempeh protects against fluid losses in Escherichia coli-infected piglet small intestine. Br J Nutr 98, 320-325.

122. Kiarie E, Slominski BA, Krause DO, et al. (2009) Gastrointestinal ecology response of piglets diets containing non-starch polysaccharide hydrolysis products and egg yolk antibodies following an oral challenge with Escherichia coli (k88). Can J Anim Sci 89, 341-352.

123. Kiarie E, Slominski BA, Krause DO, et al. (2009) Acute phase response of piglets fed diets containing non-starch polysaccharide hydrolysis products and egg yolk antibodies following an oral challenge with Escherichia coli (k88). Can J Anim Sci 89, 353-360.

124. Harris DL, Hampson DJ \& Glock RD (1999) Swine dysentery. In Diseases of Swine, 8th ed., pp. 579-600 [BE Straw, S D'Allaire, WL Mengeling and DJ Taylor, editors]. Oxford: Blackwell Science.

125. Schwartz K (2011) New (and old) tools for dysentery diagnostics. In Proceeding of the American Association of Swine Veterinarians 42nd Annual Meeting, pp. 453-458. Phoenix, AZ: American Association of Swine Veterinarians.

126. Siba PB, Pethick DW \& Hampson DJ (1996) Pigs experimentally infected with Serpulina hyodysenteriae can be protected from developing swine dysentery by feeding them a highly digestible diet. Epidemiol Infect 116, 207-216.

127. Kennedy MJ, Rosnick DK, Ulrich RG, et al. (1988) Association of Treponema byodysenteriae with porcine intestinal mucosa. J Gen Microbiol 134, 1565-1574.

128. Zhang P, Duhamel GE, Mysore JV, et al. (1995) Prophylactic effect of dietary zinc in a laboratory mouse model of swine dysentery. Am J Vet Res 56, 334-339.

129. Gast RK (2010) Pre-harvest control of Salmonella. WATT Poultry U S A 11, 16-18.
130. Van Immerseel F, Eeckhaut V, Teirlynck E, et al. (2007) Mechanisms of action of nutritional tools to control intestinal zoonotic pathogens. In Proceedings of the 16th European Nutrition Symposium, pp. 243-250. Strasbourg: World Poultry Science Association.

131. Eeckhaut V, Van Immerseel F, DeWulf J, et al. (2008) Arabinoxylooligosaccharides from wheat bran inhibit Salmonella colonization in broiler chickens. Poult Sci 87, 2329-2334.

132. Vandeplas S, Dauphin RD, Thiry C, et al. (2009) Efficiency of a Lactobacillus plantarum-xylanase combination on growth performances, microflora populations, and nutrient digestibilities of broilers infected with Salmonella Typhimurium. Poult Sci 88, 1643-1654.

133. Amerah AM, Mathis G \& Hofacre CL (2012) Effect of xylanase and a blend of essential oils on performance and Salmonella colonization of broiler chickens challenged with Salmonella Heidelberg. Poult Sci 91, 943-947.

134. Ducatelle R \& Van Immerseel F (2010) Necrotic enteritis: emerging problem in broilers. WATT Poultry USA 11, 22-24.

135. Williams RB (2005) Intercurrent coccidiosis and necrotic enteritis of chickens: rational, integrated disease management by maintenance of gut integrity. Avian Pathol 34, 159-180.

136. Collier CT, Hofacre CL, Payne AM, et al. (2008) Coccidiainduced mucogenesis promotes the onset of necrotic enteritis by supporting Clostridium perfringens growth. Vet Immunol Immunopathol 122, 104-115.

137. Jackson ME, Anderson DM, Hsiao HY, et al. (2003) Beneficial effect of beta-mannanase feed enzyme on performance of chicks challenged with Eimeria sp. and Clostridium perfringens. Avian Dis 47, 759-763.

138. Parker J, Oviedo-Rondon EO, Clack BA, et al. (2007) Enzymes as feed additive to aid in responses against Eimeria species in coccidia-vaccinated broilers fed cornsoybean meal diets with different protein levels. Poult Sci 86, 643-653.

139. Bedford MR \& Cowieson AJ (2011) Exogenous enzymes and their effects on intestinal microbiology. Anim Feed Sci Technol 173, 76-84.

140. Garcia V, Gomez J, Mignon-Grasteau S, et al. (2007) Effects of xylanase and antibiotic supplementations on the nutritional utilization of a wheat diet in growing chicks from genetic D + and $\mathrm{D}-$ lines selected for divergent digestion efficiency. Animal 1, 1435-1442.

141. Aphalajalati D, Geier MS, Hughes RJ, et al. (2012) Does the composition of intestinal microbiota determine or reflect feed conversion efficiency? Proc Aust Poult Sci Symp 23, $32-39$.

142. Turnbaugh PJ, Hamady M, Yatsunenko T, et al. (2009) A core gut microbiome in obese and lean twins. Nature 457, 480-484

143. Turnbaugh PJ, Ley RE, Mahowald MA, et al. (2006) An obesity-associated gut microbiome with increased capacity for energy harvest. Nature 444, 1027-1021.

144. Marsh T (2005) Culture-independent microbial community analysis with terminal restriction fragment length polymorphism. Methods Enzymol 397, 308-329.

145. Highlander SK (2012) High throughput sequencing methods for microbiome profiling: application to food animal systems. Anim Health Res Rev 13, 40-53. 